\title{
Violent conflict exacerbated drought-related food insecurity between 2009 and 2019 in sub-Saharan Africa
}

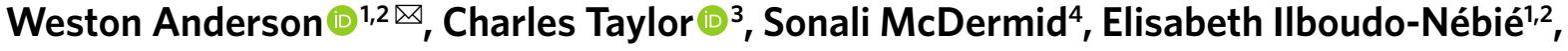 \\ Richard Seager ${ }^{5}$, Wolfram Schlenker ${ }^{(1)}{ }^{3}$, Fabien Cottier ${ }^{5}$, Alex de Sherbinin ${ }^{10}{ }^{6}$, Dara Mendeloff ${ }^{6}$ and \\ Kelsey Markey ${ }^{4}$
}

Conflict, drought and locusts are leading concerns for African food security but the relative importance and spatiotemporal scale of crises resulting from each hazard is poorly characterized. Here we use continuous, subnational data to demonstrate that the rise of food insecurity across sub-Saharan Africa that began in 2014 is attributable to an increase in violent conflict, particularly in South Sudan and Nigeria. Although drought remains a leading trigger of food crises, the prevalence of drought-related crises did not increase from 2009 to 2018 . When exposed to drought, pastoralists experienced more widespread, severe and long-lasting food crises than people living in agricultural zones. Food insecurity remained elevated in pastoral regions for 2 years following a drought, while agricultural regions returned to pre-drought food-security levels in $\sim 12$ months. The few confirmed famines during the 2009-2018 period coincided with both conflict and drought, while locusts had little effect on food security during this period.

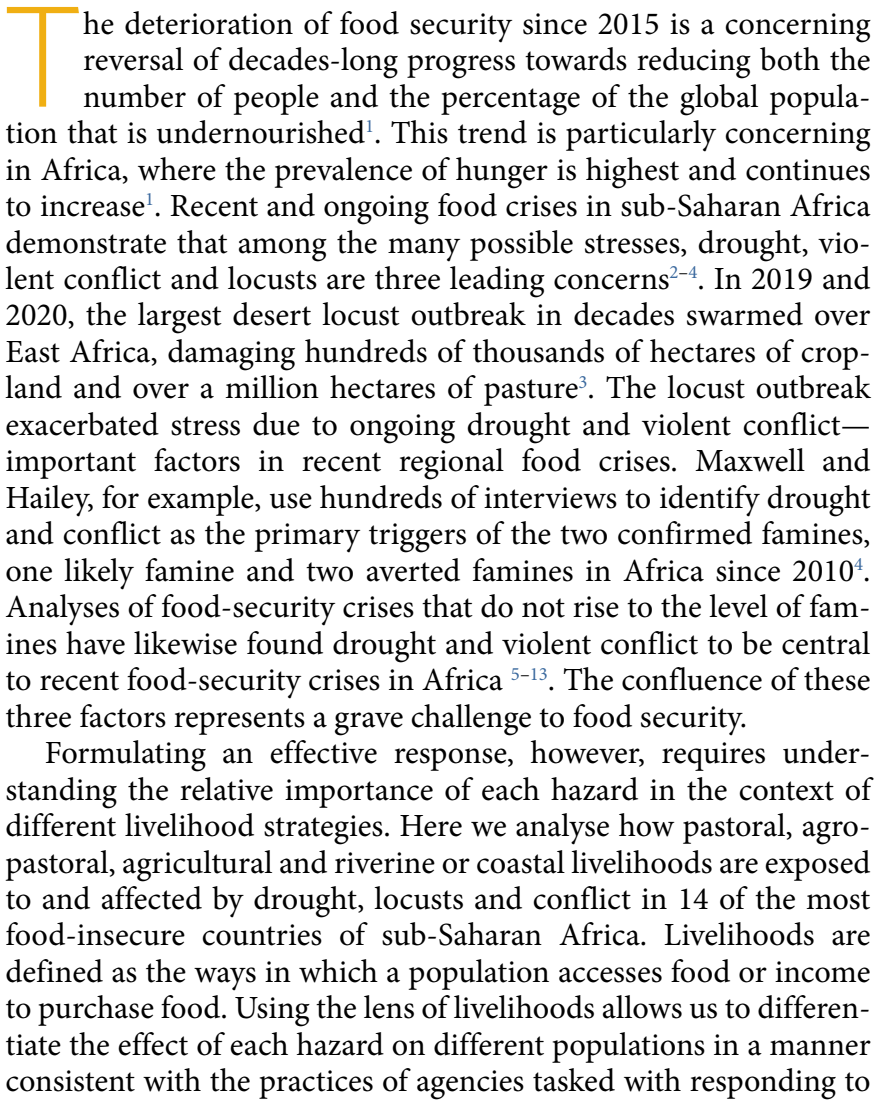

food crises ${ }^{14}$. We use the FEWS NET Integrated Food Security Phase Classification (IPC) levels to estimate the proportion of the population in different levels of food insecurity. IPC levels are determined by food-security analysts according to a consensus-based approach that encompasses available information on food consumption, livelihoods, nutritional status, mortality, food availability, market prices and exposure to hazards ${ }^{15}$. FEWS NET uses livelihood-based household food economy analyses as the analytical framework for determining IPC levels, which makes using the FEWS livelihoods an internally consistent unit of analysis. We evaluate food-security crises using the four dimensions of magnitude (the number of people affected), severity (IPC level), spatial coverage and duration of the resulting food crisis ${ }^{8}$. Our results provide insights that can better contextualize how food assistance needs have evolved differently in each livelihood zone in response to drought, conflict and locusts over the last decade.

\section{Results}

Food crises disaggregated by livelihood. The countries in this study include $\sim 70 \%$ of the population affected by hunger in Africa as estimated by the Food and Agriculture Organization (FAO) from 2009 to $2018^{1}$ with similar temporal trends between hunger in Africa and crisis-level food insecurity (IPC level $\geq 3$ ) in the studied countries (Fig. 1a). The prevalence of food insecurity was consistently highest in pastoral livelihood zones, with multiple periods of crisis-level food insecurity affecting $40-50 \%$ of the pastoral population. Agropastoral, agricultural and riverine or coastal livelihoods, on the other hand, tended to experience events in which crisis levels of food insecurity affected $10-15 \%, 5-10 \%$ and $2-4 \%$ of the population in each livelihood zone, respectively (Fig. 1c-f). The prevalence 
a

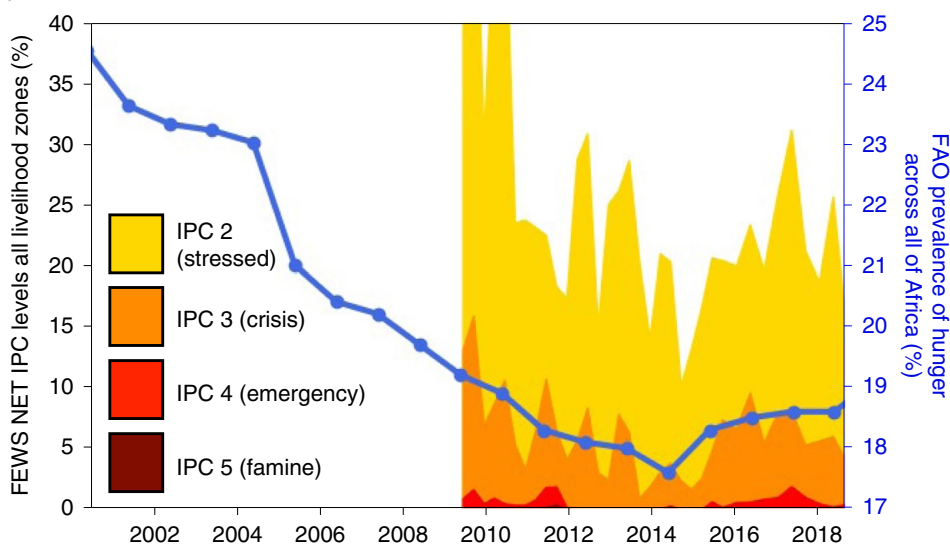

b

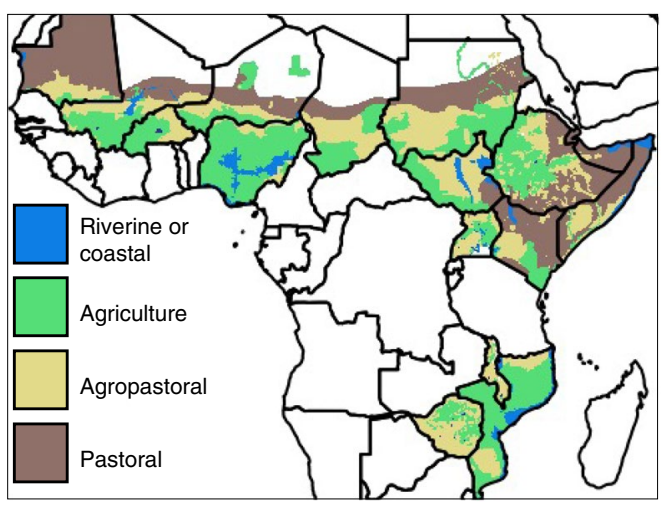

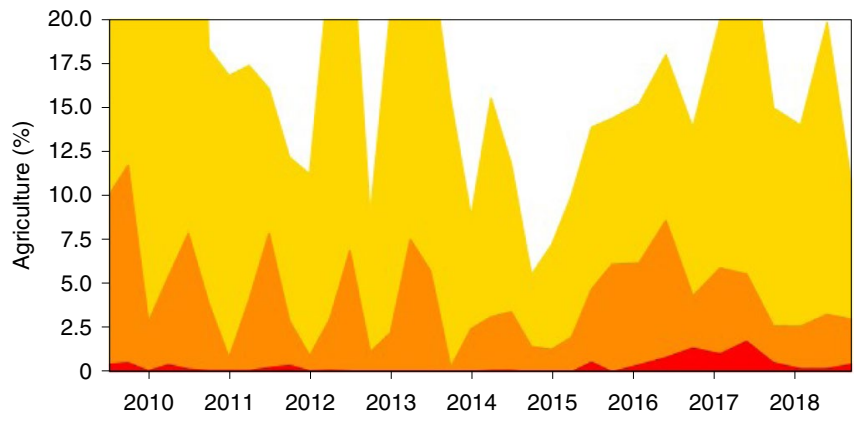

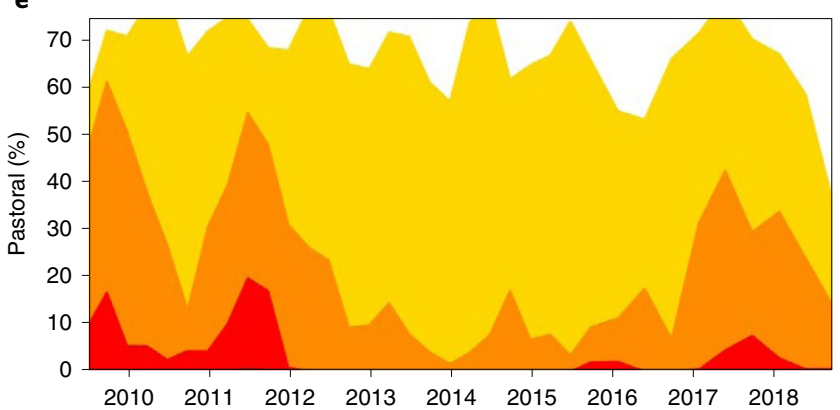

d

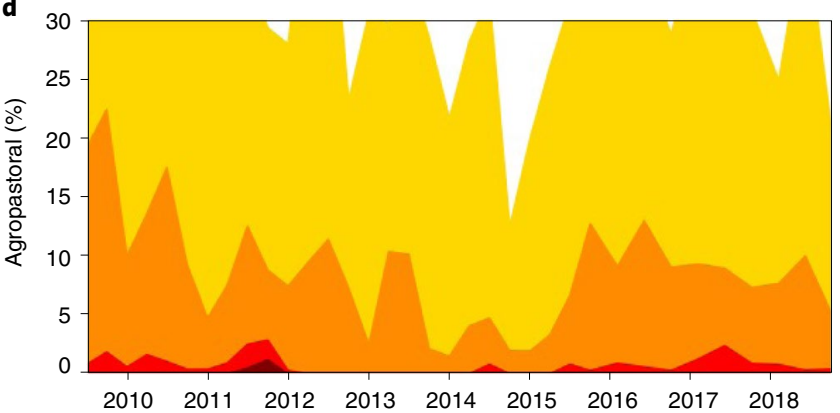

f

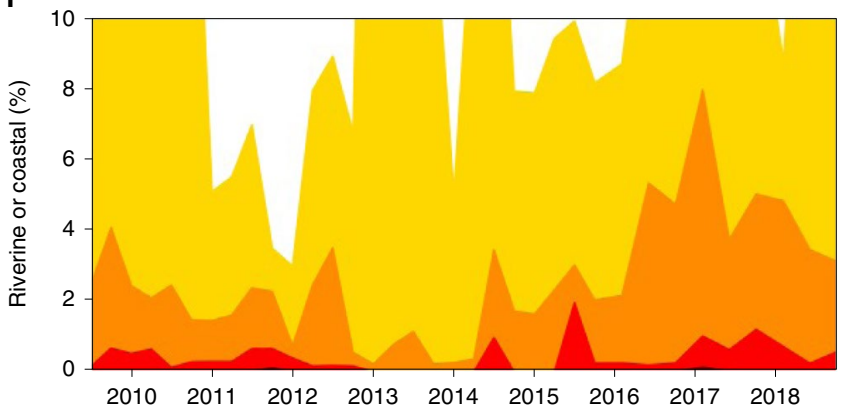

Fig. 1 | Food-insecure population by livelihood zone. a, Percentage of the population living in areas classified in each IPC level across all livelihood zones in countries included in the analysis; the blue line indicates the prevalence of hunger across all of Africa. $\mathbf{b}$, Livelihood zones in the countries included in this analysis; uncoloured areas are excluded from further analysis. c-f, Percentage of the population living in areas classified in each IPC level in agricultural (c), agropastoral (d), pastoral (e) and riverine or coastal (f) livelihoods zones. Note the differing y axes in c-f.

of crisis levels of food insecurity has increased across all livelihoods since 2014. To understand what causes food insecurity in each livelihood zone, we will analyse the hazards to which each zone is exposed and the response of food security to those hazards using the framework (exposure to a hazard $) \times($ sensitivity $)=($ impact $)$.

Sensitivity of livelihoods. Pastoralists not only experienced more frequent crisis levels of food insecurity compared with other livelihoods, they were also exposed to substantially more variable hydroclimate conditions, more frequent conflict and more frequently exposed to locusts (Fig. 2; $P<0.01$ for all pairwise comparisons between pastoralist and other livelihoods using two-tailed $t$ test). Pastoral and agropastoral livelihoods in nearly every country were associated with more variable hydroclimate (Figs. $1 \mathrm{~b}$ and $2 \mathrm{~b}$ ) while increased levels of conflict tended to be in East Africa and locusts were most prevalent in the Sahel. More variable hydroclimate conditions in pastoral areas probably indicates that these areas are unsuitable for purely sedentary agricultural livelihoods.
The relationship between food insecurity and drought or violent conflict differed by livelihood strategy (Fig. 3). Here we assess sensitivity to a hazard as the severity of food crisis that is associated with exposure to that hazard. More severe levels of food insecurity in pastoral and agropastoral zones were associated with drier conditions in the preceding year, while the relationship in agricultural and riverine or coastal zones was less strong. Crisis levels of food insecurity in pastoral zones overwhelmingly co-occurred with preceding dry conditions. These results agree with those of Coughlan de Perez et al., who demonstrate that droughts in East Africa affect pastoralists more strongly than non-pastoral livelihoods ${ }^{16}$.

Severe levels of food insecurity were associated with more frequent conflict, most strongly in agricultural livelihood zones (Fig. 3g), followed by agropastoral and riverine or coastal zones. The relatively few instances of famine-level food insecurity occurred during times of both conflict and drought (Fig. 3 and Supplementary Fig 1), which is consistent with research finding that 


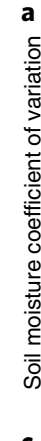
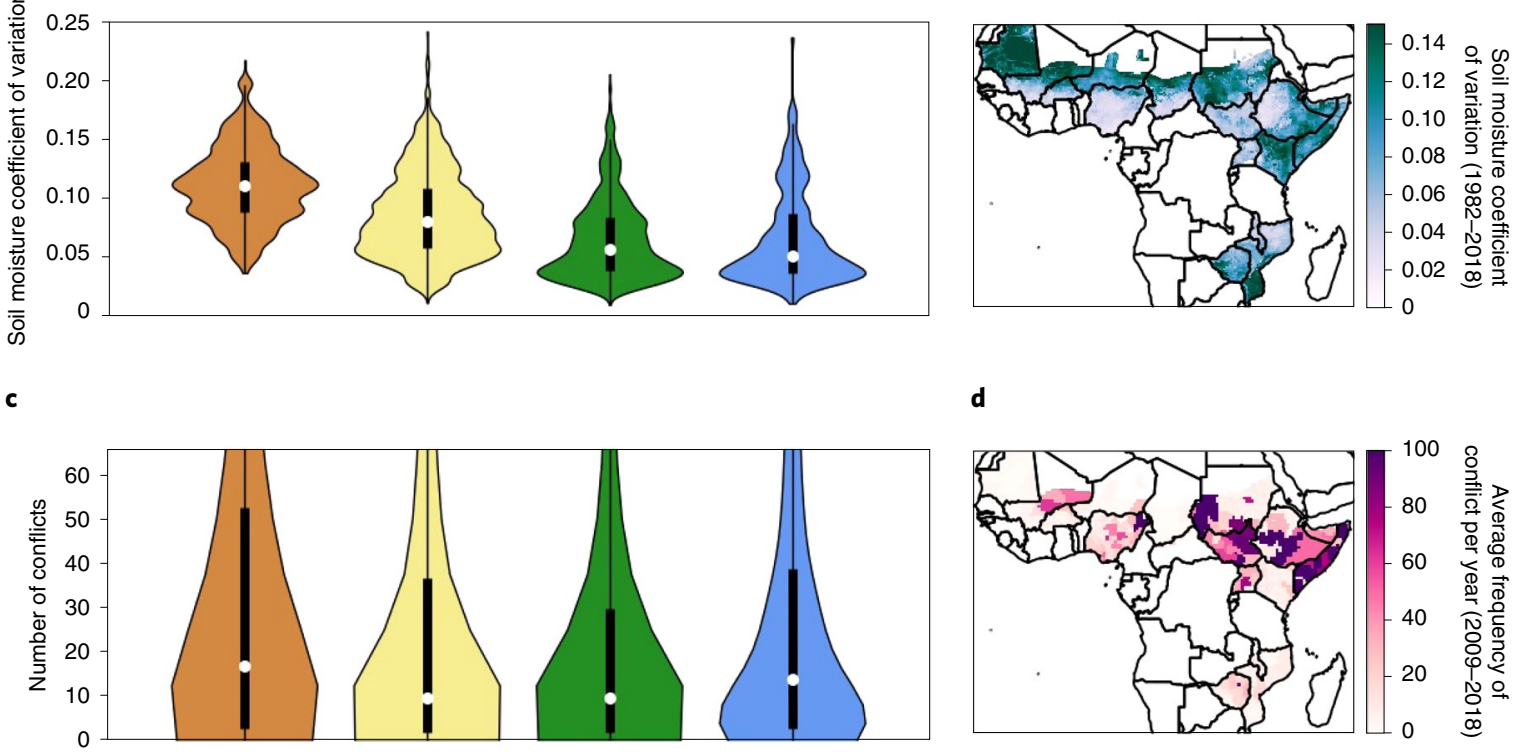

d
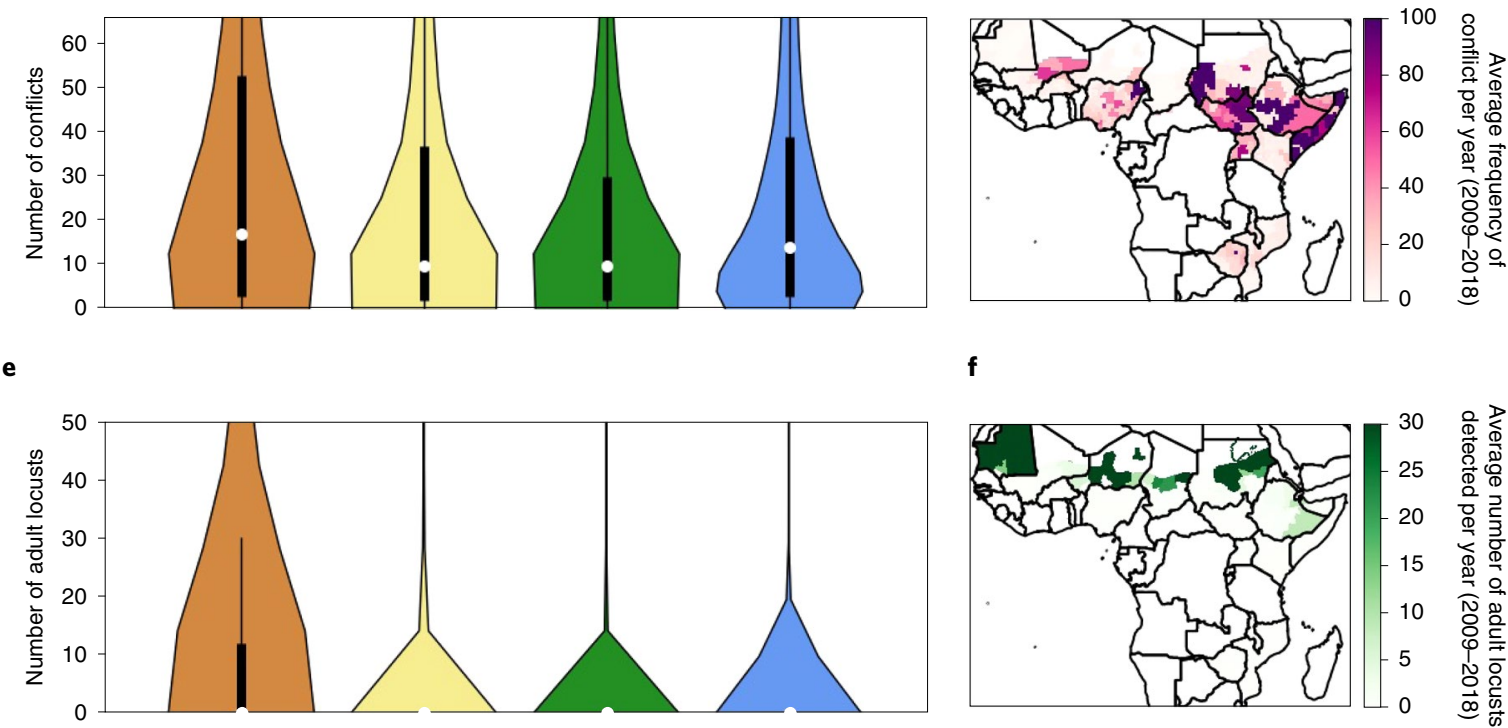

f

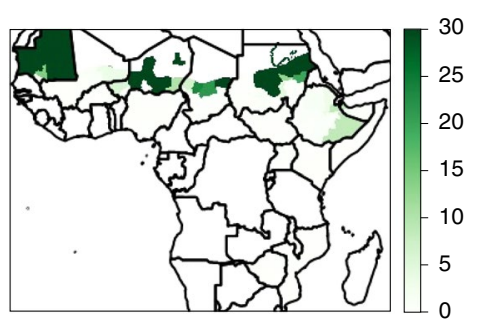

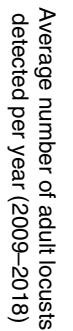

g

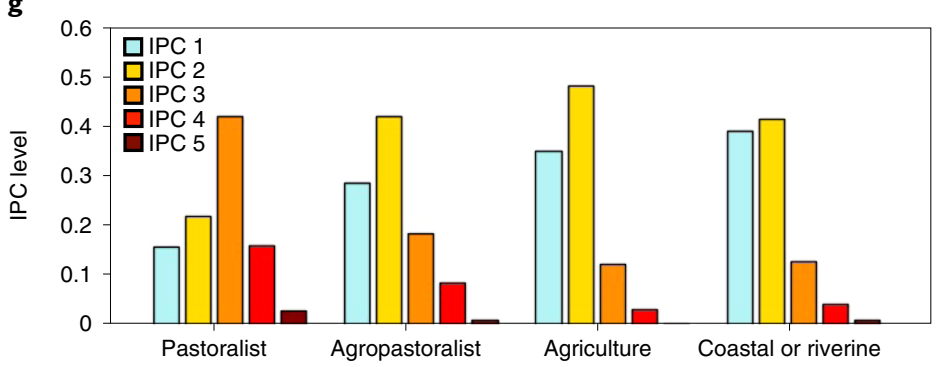

h

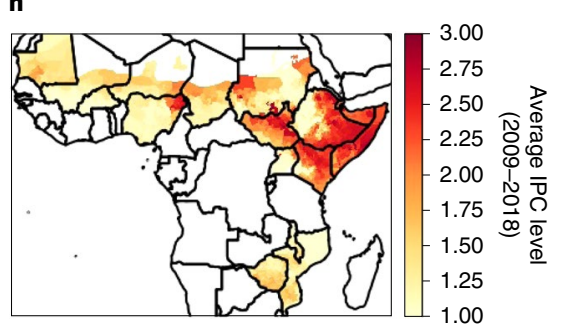

Fig. 2 | Prevalence of drought, locusts and conflict, by livelihood zone. a-f, Violin plots (shaded) showing the probability density functions of soil moisture coefficient of variation (a), frequency of conflict (c) and incidence of locusts (e) for different livelihood zones and the corresponding spatial plots (b,d,f). The inset boxplots in a,c,e show the interquartile spread in black and the median in white. $\mathbf{g}$, $\mathbf{h}$, IPC level distributions across livelihood zones ( $\mathbf{g}$ ) and plotted spatially (h). Coloured bars in $\mathbf{g}$ correspond to IPC 1 (minimal stress; light blue), IPC 2 (stressed; yellow), IPC 3 (crisis; orange), IPC 4 (emergency; red) and IPC 5 (famine; maroon).

the presence of conflict can make populations more vulnerable to subsequent shocks, such as drought ${ }^{17}$.

Adult locusts were more frequently present during relatively food-secure years, even after accounting for their increased presence in non-drought years (Fig. 3 and Supplementary Fig. 1). This increased frequency may be a result of locusts seeking out healthy crops as a food source, but the lack of association with food security implies that while extreme numbers of locusts may affect food security at a regional scale, they have not played a leading order role over the past decade. We used information on the presence of adult locusts in this analysis, but we tested the sensitivity of using locust swarms, of which there were considerably fewer observations, and found that they too were disproportionately present in pastoral areas (Supplementaty Fig. 2) and showed no relation to food-security status. We caution, however, that the intensity of locust swarms during the 2009-2018 period did not reach the intensity of the 2019-2020 locust swarms, leaving open the possibility that locusts in extreme numbers may still affect regional-scale food security.

Characteristics of drought-related food crises. Differences in the relationship between food security and drought are not limited to the severity dimension of food crises. We find that, when exposed to droughts of a similar spatial extent and relative magnitude, a greater percentage of pastoralist area and population entered crisis levels of food insecurity compared to other livelihoods. In pastoralist areas $\sim 40 \%$ of the area and $\sim 60 \%$ of the population reached crisis levels of food insecurity compared with $15-20 \%$ of both population and area in other livelihood zones (Fig. 4). 

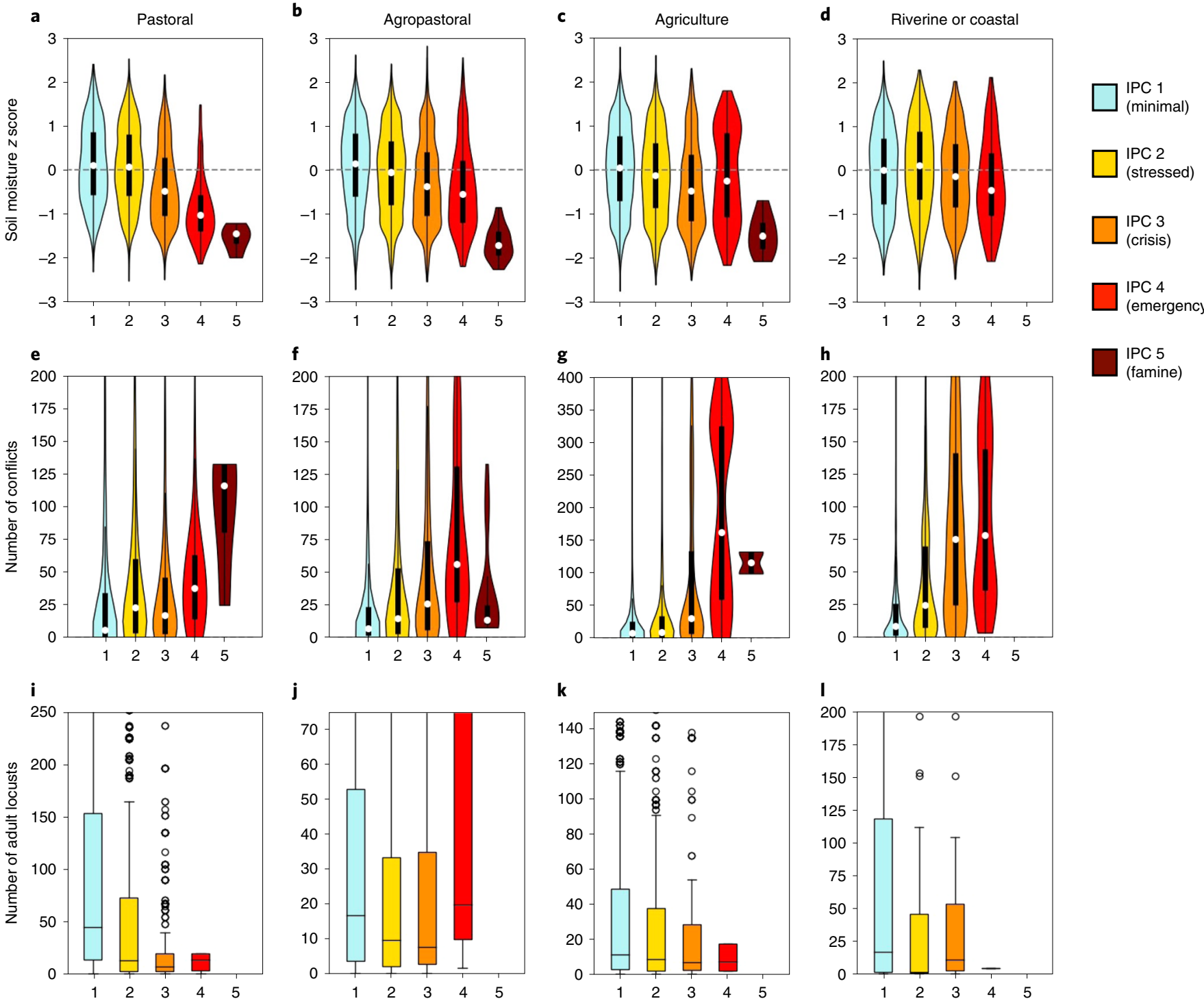

\section{j}

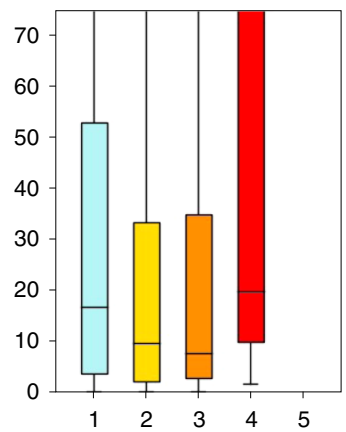

\section{k}

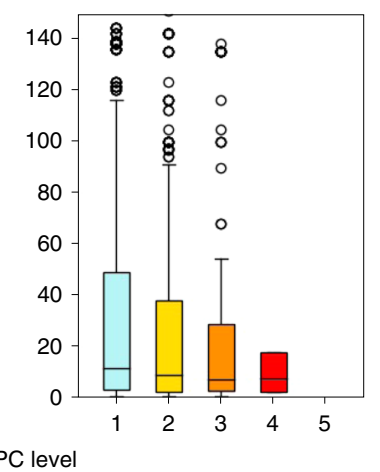

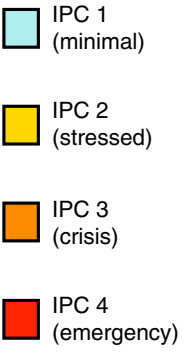

(famine)

Fig. 3 | Sensitivity to drought, locusts and conflict, by livelihood zone. a-I, Distribution over the year prior to food-insecurity events (IPC levels 1-5) of soil moisture z scores (a-d), conflict frequency $(\mathbf{e}-\mathbf{h})$ and locusts $(\mathbf{i}-\mathbf{I})$ in pastoral $(\mathbf{a}, \mathbf{e}, \mathbf{i})$, agropastoral $(\mathbf{b}, \mathbf{f}, \mathbf{j})$, agricultural $(\mathbf{c}, \mathbf{g}, \mathbf{k})$ and riverine or coastal $(\mathbf{d}, \mathbf{h}, \mathbf{l})$ livelihood zones. Violin plots (shaded) in a-h depict probability density functions of drought and conflict, which are also depicted using the inset boxplots. Locust incidence boxplots in $\mathbf{i}-\mathbf{I}$ show interquartile spread in black and median in white. Note the differing $y$ axes.

The time evolution of food insecurity differed substantially as well. Populations experiencing emergency levels of food crisis peaked later in pastoral livelihood zones than in agricultural livelihood zones; food insecurity persisted for longer in pastoral livelihood zones as well. It took 2 years from the onset of drought to return to pre-drought levels of food security in pastoralist regions, while in agricultural livelihood zones food security improved more quickly following the return of normal rains. This discrepancy was particularly visible in the associated crude death rates for each livelihood zone. In pastoral livelihood zones death rates gradually increased for about 9 months followed by a gradual decrease for 12-15 months back to levels comparable to those at drought onset. In agricultural livelihood zones a sharp increase in the crude death rate for 3-6 months was immediately followed by an equally precipitous decrease, indicating a more severe hunger season than normal preceding harvest of the next crop. This suggests that at regional scales droughts do not generally disrupt planting a new crop substantially enough to trigger widespread food insecurity in agricultural livelihood zones. Riverine or coastal livelihoods showed little increase in the crude death rate in response to drought.

Market prices of staple foods were likewise higher following droughts compared to the expected seasonality of food prices as illustrated by the subsequent non-drought years. While food price data at local markets were not dense enough to disaggregate by livelihood zone, Fig. 4 illustrates country-average prices for those countries containing each livelihood zone. Food prices peak coincident with the maximum extent of total precipitation and soil moisture deficits over the previous year. Crude death rates across livelihoods, which are derived from IPC data following Maxwell et al. ${ }^{8}$, similarly peak coincident with drought and market price peaks.

While we considered that observed relationships between drought and food security may be confounded by relations between drought and conflict, we found no systematic relation between drought and either the frequency of conflict or deaths related to 

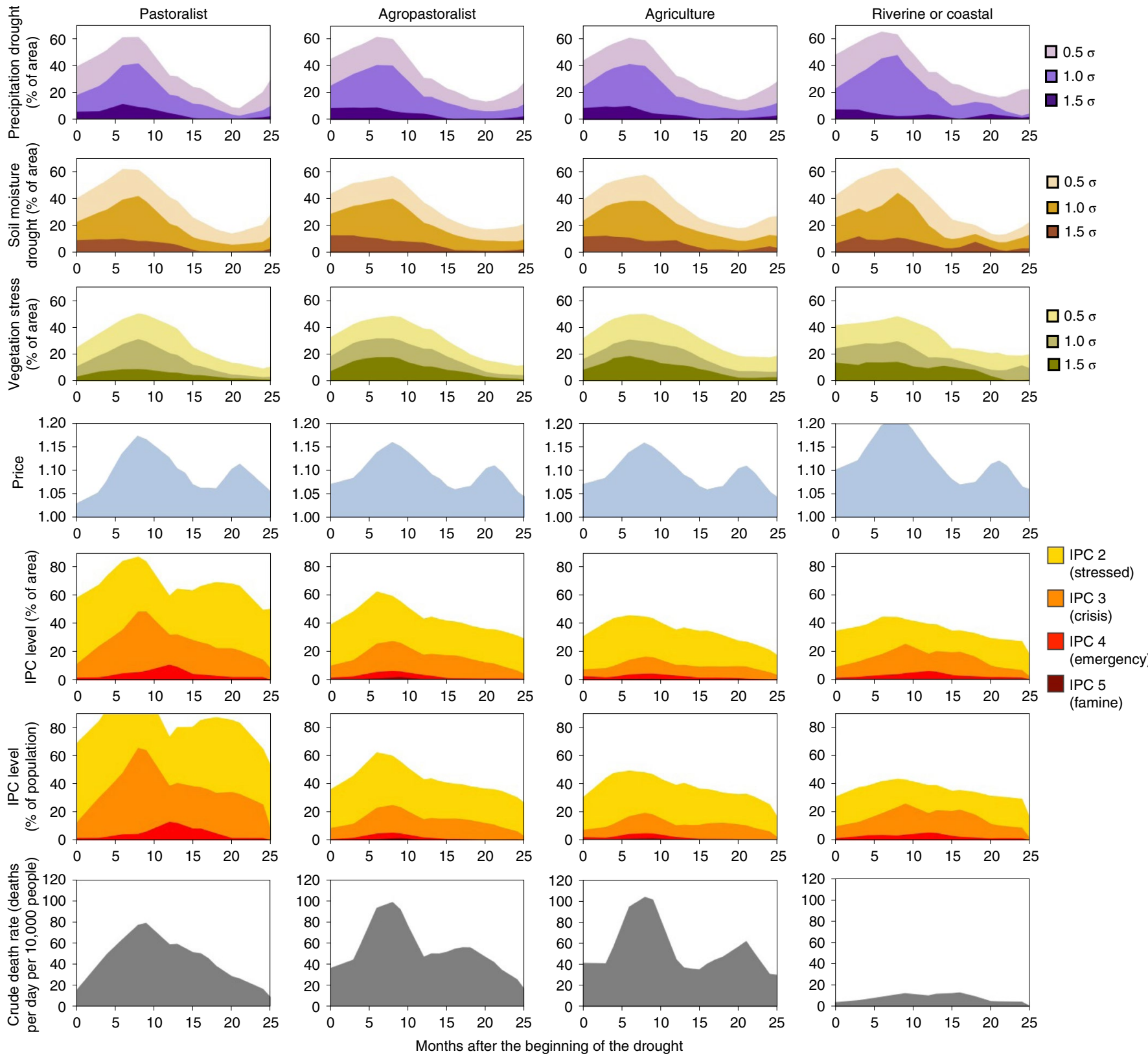

Fig. 4 | Food security crises during droughts in each livelihood zone. Evolution of the percentage of area in precipitation drought, soil moisture drought or vegetative stress, and the price of staple foods, the percentage of the population living in areas classified as in each IPC level, the percentage of area in each IPC level, and the crude death rate in pastoralist, agropastoralist, agricultural and riverine or coastal livelihoods from the onset of the drought (month 0 ) to 2 years later (month 24).

conflict (Supplementary Fig. 3). Conflict may be affected by environmental stress in some cases but the relationship across Africa in recent decades is complex and context specific ${ }^{18-22}$.

Attributing food-security crises to drought and conflict. Food insecurity as measured by either population or spatial extent is concentrated in just a handful of countries, and coincides with intermittent droughts and an increase in violent conflict (Fig. 5a,b). We note that these factors may coincide with economic contractions and price inflation which can further exacerbate food crises, which we discuss in the case of Nigeria and South Sudan. Across the study region, there is neither a trend towards drier soils (Fig. $5 \mathrm{~d}$ ) nor a trend in the percentage of the population affected by drought (Fig. 5c). Conflict, however, has become more frequent in nearly all locations, with the largest populations affected in Nigeria and Ethiopia. Both the extent of conflict and the percentage of the population affected by conflict are concentrated in Sudan, South Sudan, Ethiopia, Nigeria and Somalia (Fig. 5e,f). While exposure to drought remained relatively constant, food-security crises trended downward until 2014, after which time they have been increasing (Fig. $5 \mathrm{c}, \mathrm{e}$ ). The early part of the record includes large food-insecure populations in Kenya, Somalia and Ethiopia, followed by a rise of food insecurity in Nigeria and South Sudan after 2014 (Fig. 5a,b). The only statistically significant trends towards worsening food crises-those in northeast Nigeria and South Sudan-co-occurred with increases in violent conflict. But in other states, such as Ethiopia, Somalia, Mali and Sudan, significant trends towards more frequent violent conflict were not associated 
a

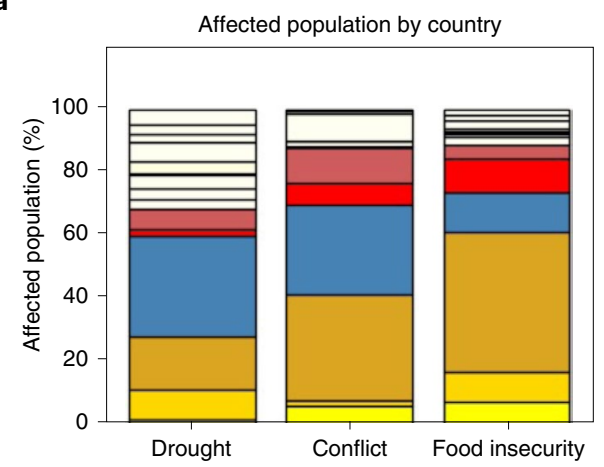

c
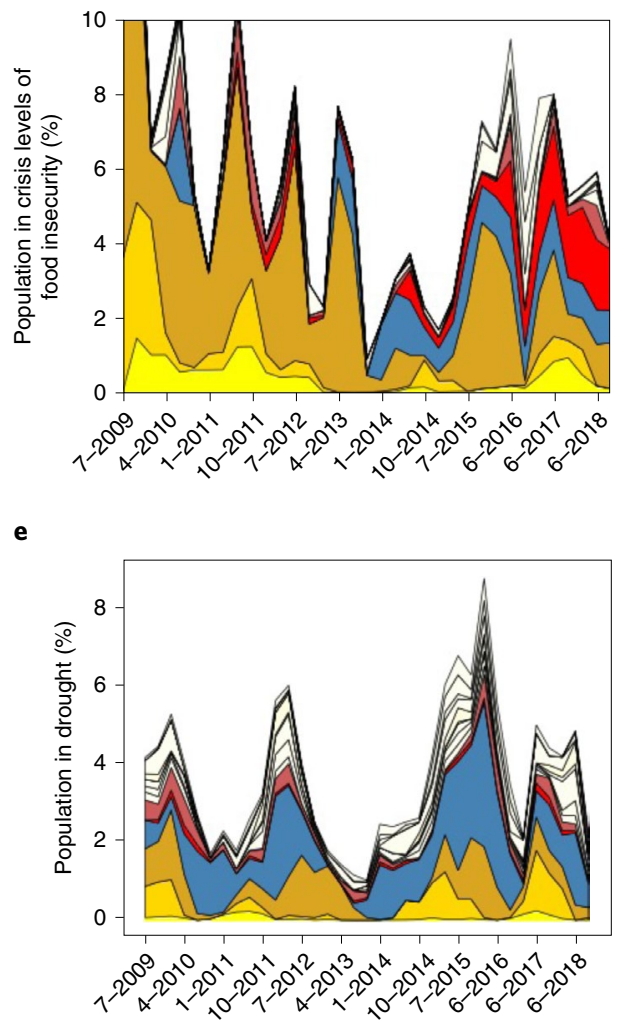

g

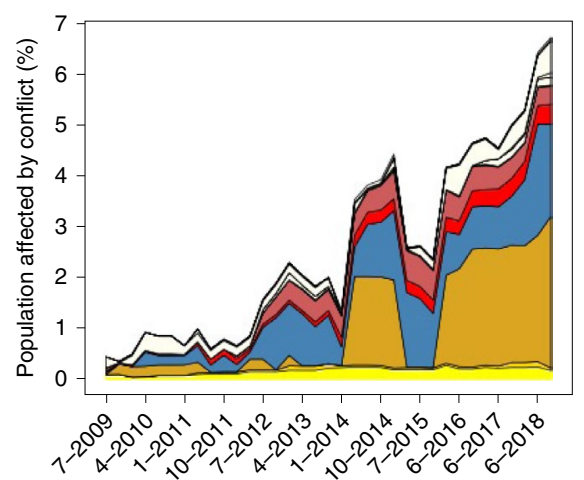

b

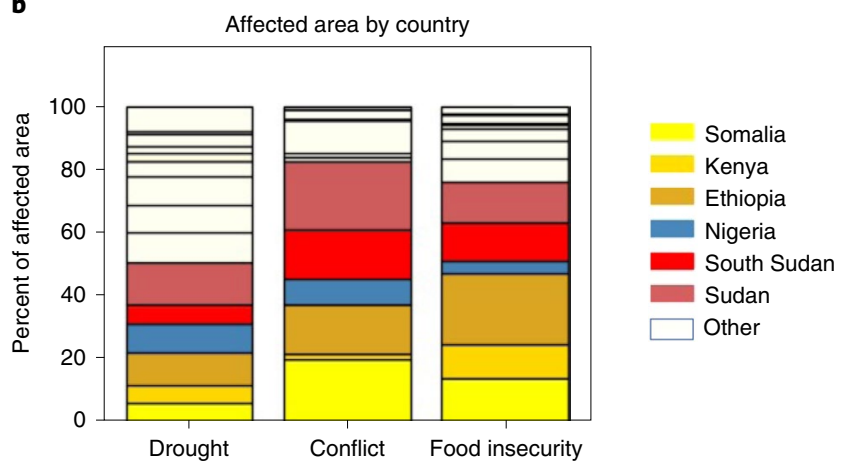

d

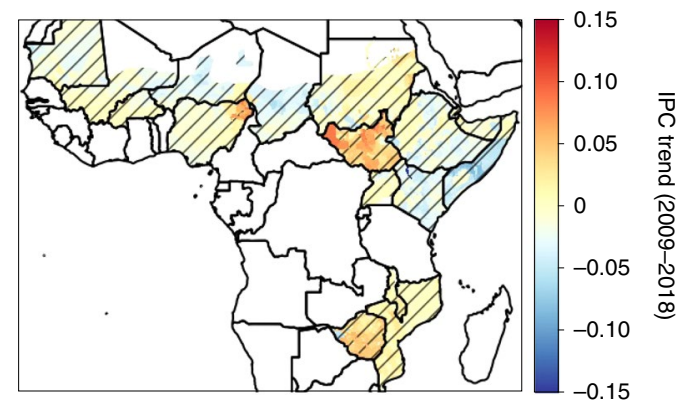

f

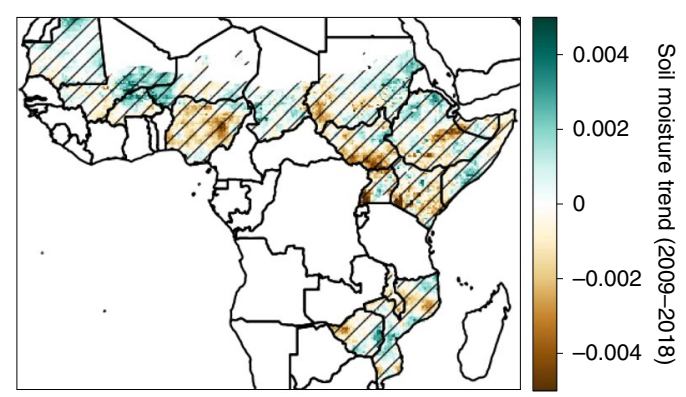

h

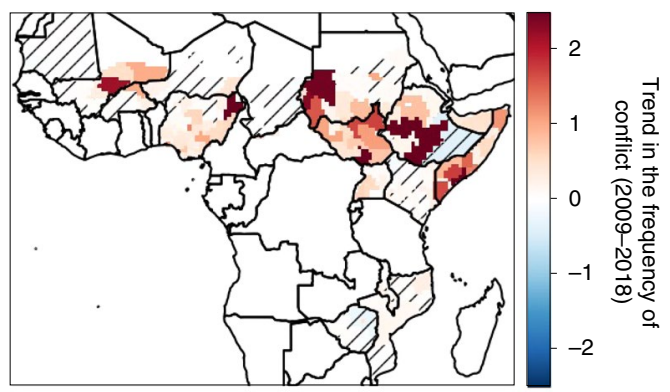

Fig. 5 | Distribution of hazards and trends in hazards by country. a,b, The prevalence of drought, conflict and crisis levels of food insecurity (IPC level $\geq 3$ ) in each country as measured as a percentage of total affected population (a) or area (b) over the entire study period. Six of the 14 countries are colour coded. $\mathbf{c}, \mathbf{e}, \mathbf{g}$, Variation over time of the percentage of the total population across all study countries living in areas classified in crisis levels of food insecurity (c), drought (e) and conflict (g). d,f,h, Spatial distribution of the trend over 2009-2018 of the IPC level (d), soil moisture (f) and frequency of conflict in study countries (h), with insignificant $(P>0.05)$ trends hatched. 

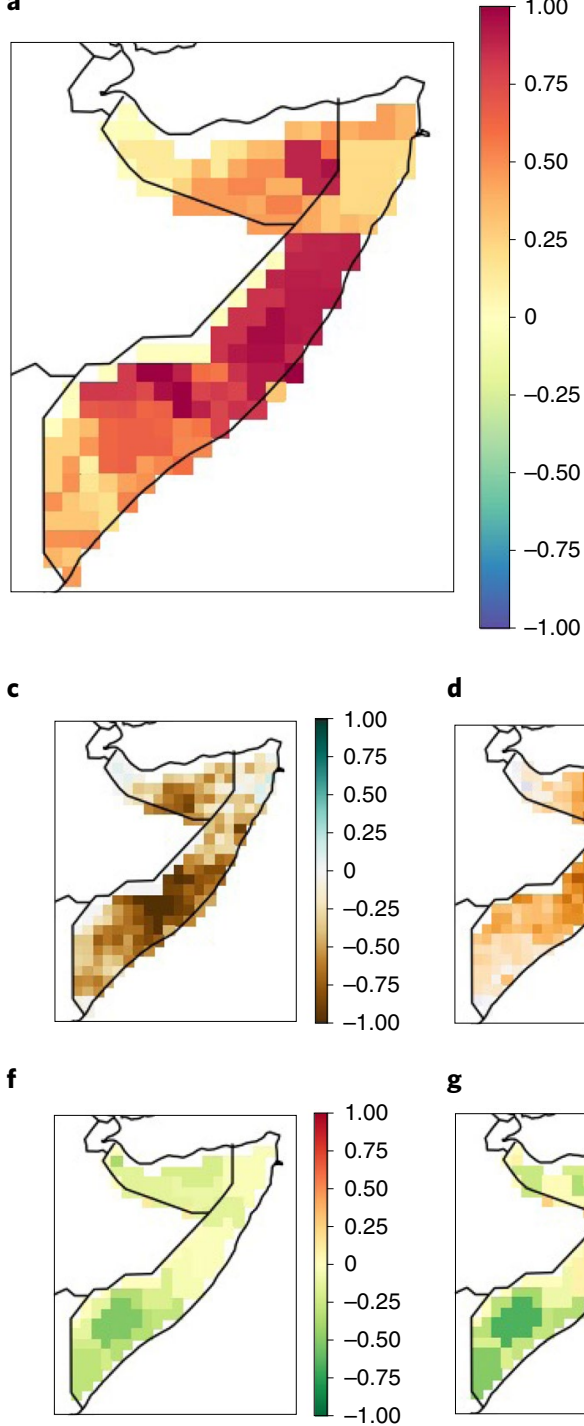

d

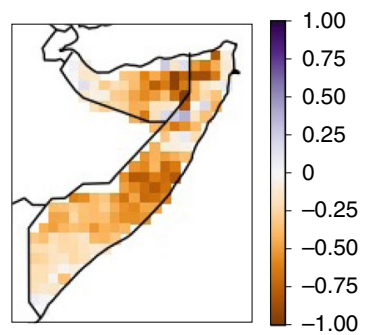

g

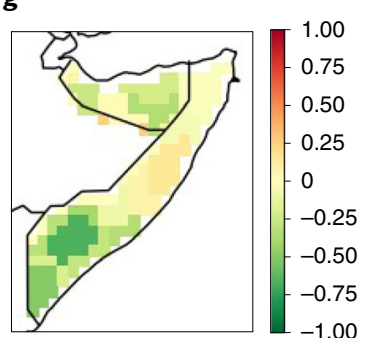

b

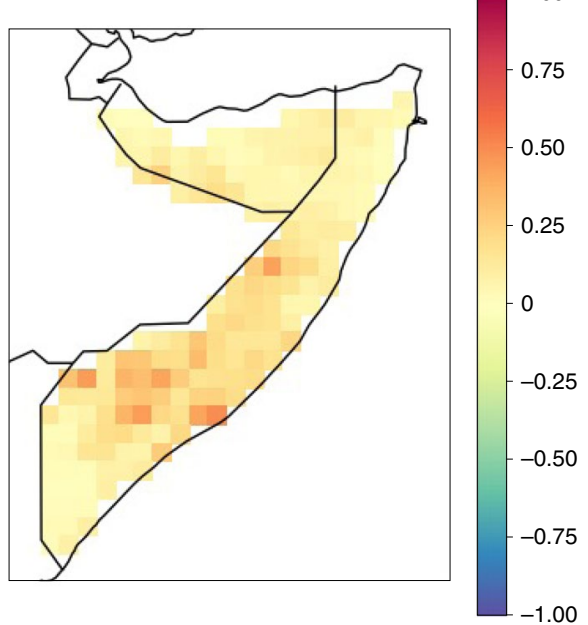

e

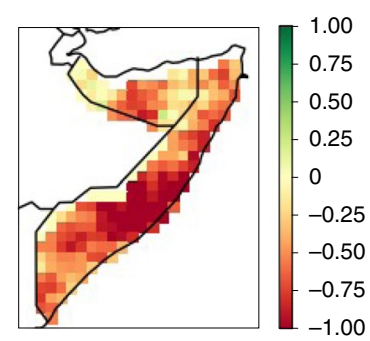

h

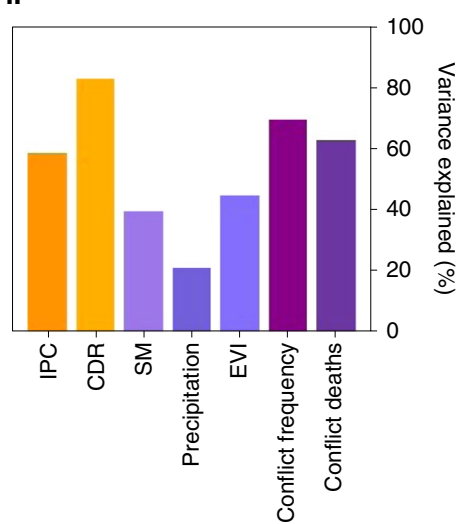

i

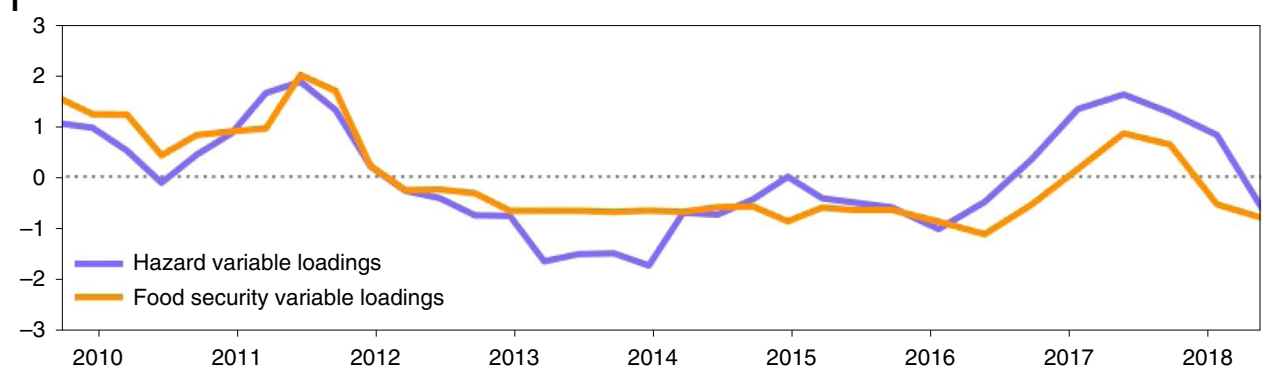

Fig. 6 | Maximum covariance analysis mode 1 for Somalia. Spatial loading pattern of mode 1 on food-security variables and hazard variables. Mode 1 in Somalia explains $46 \%$ of the covariance between food-security variables and hazard variables. a,b, Food-security variables include IPC level (a) and crude death rate (b). c-g, Hazard variables include soil moisture (c), precipitation (d), vegetation stress (e), the frequency of conflict (f) and the deaths attributable to conflict $(\mathbf{g})$. h, Variance explained by mode 1 for each variable. CRD, crude death rate; SM, soil moisture. i, Time-expansion coefficients for mode 1. All units are standardized spatial loadings and time-expansion coefficients. See Methods for details. Somalia mode 1 is a mixed conflict and drought mode based on the spatial loading patterns and variance explained for each variable. 

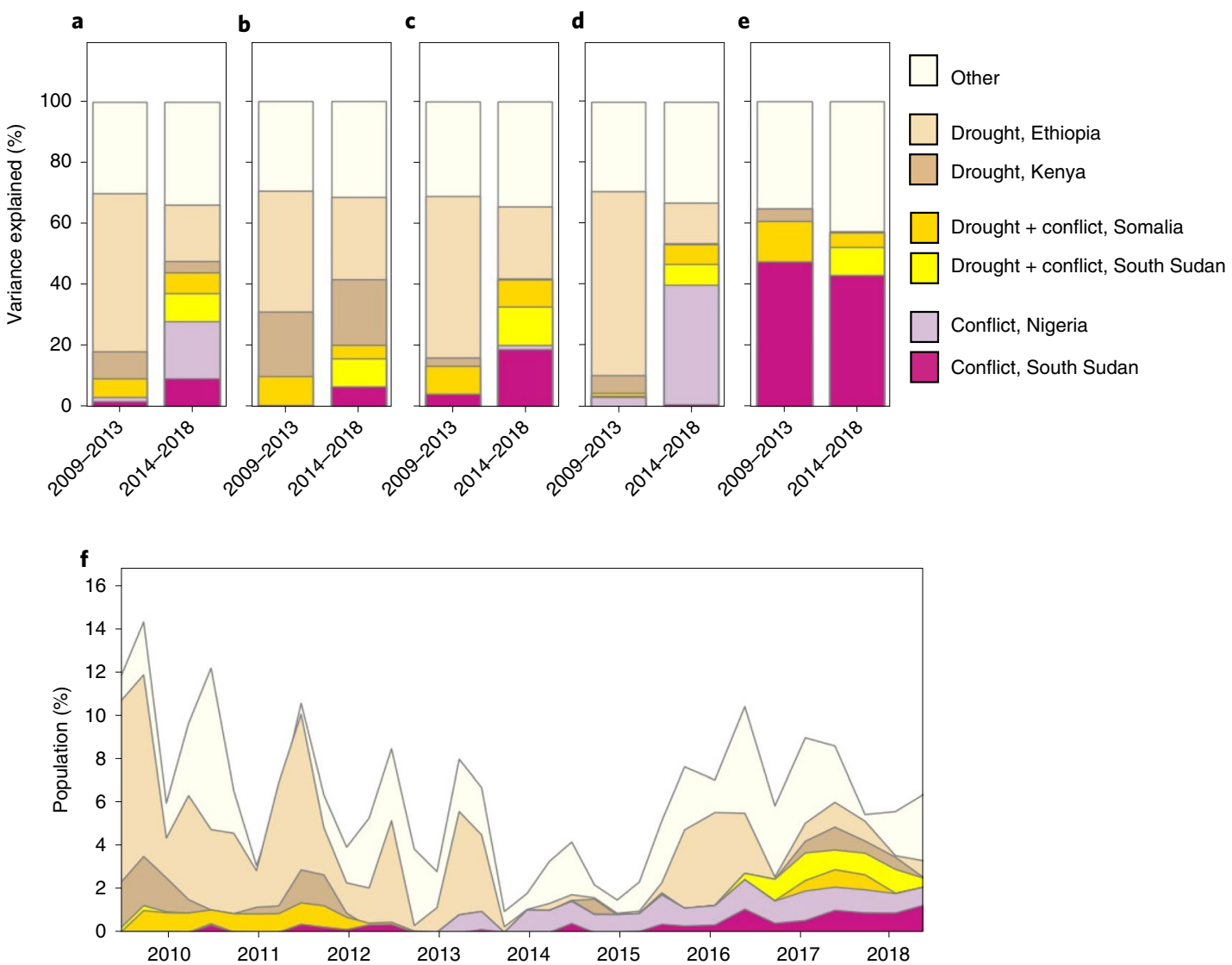

Fig. 7 | Food crisis attribution by livelihood zone. Attribution of the primary trigger of food insecurity for populations living in areas classified as being in crisis levels of food insecurity (IPC level $\geq 3$; see text for discussion of triggers). a-e, Percentage of the population of all 14 study countries living in areas classified as IPC level $\geq 3$ attributed to each trigger in total (a) and in each livelihood zone: pastoral (b), agropastoral (c), agricultural (d) and riverine or coastal (e). 'Other' indicates populations in food crisis not covered by the leading modes of the maximum covariance analysis in Ethiopia, Kenya, Somalia, Nigeria or South Sudan. f, Population living in areas classified as IPC level $\geq 3$ (crisis) as a percentage of total population in study countries over time.

with trends towards food insecurity (Fig. 5). These findings highlight that while armed conflict is associated with negative effects on food security (Figs. 1 and 3), the effect can vary depending on the duration of the conflict and how it transforms local institutions and livelihoods ${ }^{21-24}$.

To estimate the relative importance of drought or conflict in each country, we perform a maximum covariance analysis on a country-by-country basis (Methods), which identifies how spatial patterns in drought and conflict vary synchronously with spatial patterns in food security. Figure 6 illustrates an example for the first mode for Somalia. This mode attributes food insecurity to a combination of drought and conflict. Protracted conflict and adverse economic conditions made the population of Somalia vulnerable to drought in the 2010-2011 and 2017 food crises, which disproportionately affected minority and marginalized groups ${ }^{4,6-8,25,26}$. There is a spatial association of drought metrics (Fig. 6c-e) with food insecurity (Fig. 6a,b), such that both are most intense in south central Somalia. In central Somalia there is an association of food insecurity with increased conflict (Fig. 6f,g); in early 2011, for example, central Somalia was both the only area in a food crisis and the only area simultaneously experiencing drought and violent conflict. Elsewhere in Somalia drought is dominant. The time variation (Fig. 6i) describes drought-related food insecurity in 2010, 2011 and 2017. The persistence of violent conflict during the drought in 2011 further contributed to the late and insufficient humanitarian response in some areas owing to operating restrictions imposed on relief agencies and the fear of food aid being diverted by Al-Shabaab ${ }^{6,7,26}$. The number of incidents of conflict in Somalia, however, actually peaked in 2013 and 2014 and was lower during both major droughts of 2010-2011 and $2017^{25}$.

Drought in Ethiopia is the dominant contributor to African food insecurity in the 2009-2013 period, while conflict in South Sudan and Nigeria during the 2014-2018 period became increasingly important (Figs. 5 and 7). Food-security crises in Ethiopia and Kenya were primarily triggered by drought-with droughts straining food systems in parts of Ethiopia nearly every year, including major events in 2009, 2011, 2015 and 2017 9,27,28. These droughts acted on populations made vulnerable by land fragmentation, lack of land tenure, lack of infrastructure, political marginalization and armed conflict $^{9,10}$. In Nigeria, by contrast, violent conflict was the primary trigger of food-security crises (Fig. 7). The northeastern state of Borno is the epicentre of violent conflict related to Boko Haram, which has disrupted livelihoods, displaced people and reduced households' ability to access food ${ }^{11-13}$, while resource-related conflict in the central northern part of Nigeria has led to increasingly frequent farmer-herder conflicts and cattle theft ${ }^{13}$. Conflict furthermore affected food prices after 2016 when oil pipeline sabotage in the Niger Delta reduced national oil production by over $50 \%{ }^{29}$. In southern Sudan and South Sudan the recent increase in food insecurity is attributable in part to a sustained increase in violent conflict and in part to erratic rains from $2017-2019^{8,21,30}$. Armed conflict disrupted food production directly, but also disrupted oil production, which led to a collapse of government revenue, an increase in currency printing and high levels of inflation ${ }^{31}$. It is notable that the two 
confirmed famines during this time period-South Sudan in 2017 and Somalia in 2011-occurred in the presence of both drought and conflict (Supplementary Fig. 1).

Over the entire study period, drought became slightly less important as a source of food insecurity, while conflict became relatively more important (Fig. 7). The change was particularly pronounced in agricultural livelihood zones due to the simultaneous increase in conflict-related food insecurity in Nigeria and South Sudan, and the decrease in drought-related food crises in Ethiopia. In pastoral and agropastoral zones a more modest relative rise in conflict-related food insecurity was attributable to the rise in violent conflict in South Sudan. Riverine and coastal zones are less affected by drought in general (Figs. 2-4), meaning that conflict is the leading trigger of food insecurity both before and after 2014 in these zones (Fig. 7)

Finally, we find that the character of food-security crises associated with drought and conflict are considerably different. Drought-related food-security crises were spatially widespreadoften occurring at a similar spatial scale as the drought itself (Fig. 4) - and tended to last 1-2 years (Fig. 7 and Supplementary Fig. 10). Conflict-related food-security crises were persistent, severe and had varying spatial scales (Figs. 5 and 6). The conflict-related crises in Nigeria and South Sudan were years-long, but were spatially confined in the case of Nigeria to the northeast of the country while crises were more widespread in South Sudan (Fig. 5, and Supplementary Fig. 10). The years-long persistence of violence in South Sudan and Nigeria has been a major contributor to the post2014 increase in the prevalence of food crises across sub-Saharan Africa (Fig. 7).

\section{Discussion}

This study finds that the rise in food insecurity across sub-Saharan Africa that began in 2014 is attributable to violent conflict, particularly in South Sudan and Nigeria. Conflict-related food crises increased in relative importance compared to drought across all livelihood zones from 2009 to 2018 . Drought was the primary trigger of food-security crises prior to 2014, and remained important afterwards, but there has been neither an increased incidence of drought nor drought-related food crises during the period of rising food insecurity. We furthermore find that locusts had little association with food crises in any livelihood zone from 2009 to 2018, but we caution that this finding is for a period with locust swarms that do not reach the intensity of the 2019-2020 swarm.

Assumptions and limitations. Our analysis should be understood as characterizing food-insecurity levels by livelihood and identifying the primary triggers, or combinations of triggers, for specific food crises rather than providing a means of discriminating between plausible mechanisms linking triggers to levels of food insecurity. In Fig. 4, for example, we demonstrate that drought events cause relatively higher peaks in food prices than would otherwise be expected, but droughts could also affect food security by destroying livelihoods and causing the collapse of entitlements in the absence of food price changes. Likewise, we rely on detailed analyses of relevant food crises to identify the causal mechanisms linking violent conflict to food insecurity but do not attempt to generalize the importance of one mechanism over another.

Our analysis is furthermore limited by data availability. Owing to the paucity of detailed, longitudinal measurements of food insecurity and the imprecision of the IPC levels, our analysis is constrained to identifying causes of and trends in categoric classifications of food insecurity at the synoptic scale. The IPC process was not designed for research purposes; it is complex, includes many different information streams and is carried out by different teams to estimate the proportion of the population currently in various levels of food insecurity. The lack of detailed, spatially and temporally continuous information on food insecurity has become a major barrier to food-security research at a time when increasingly detailed information is becoming available on the economic, abiotic, biotic and human hazards that affect food security. In this context, IPC levels represent a valuable source of information, but should not be considered a replacement for more frequent, precise measurements of food security that are still needed for many research purposes. Likewise, our estimates of crude death rate are conservative IPC-derived estimates, as in Maxwell et al. ${ }^{8}$, rather than direct observations, and do not replace the need for direct data collection as a means of improving food-security research and monitoring.

Implications of findings. Our results highlight the growing importance of violence as a trigger of food crises in all livelihood zones. Past work demonstrates that the pathways by which conflict contributes to food crises include restricting operations of humanitarian organizations ${ }^{26}$, impeding the flow of information and food aid ${ }^{6,7,26}$, disrupting livelihoods and households' ability to access food ${ }^{11-13}$, destroying infrastructure to disrupt regional economic activity ${ }^{29,31}$ and disrupting food production ${ }^{32}$. Further work is needed, however, to characterize the relative importance of each of these pathways and to identify means of predicting or monitoring these disruptions.

When considering relative differences among livelihoods, we find that those engaging in pastoral livelihoods, who account for over a quarter of the population in Africa ${ }^{33}$, substantially differed in both exposure and sensitivity to each hazard. Pastoralists were exposed to more variable hydroclimate conditions, exposed more frequently to locusts and tended to be less food secure than those living in agricultural livelihood zones. When exposed to droughts, pastoralists experienced more spatially widespread, severe and long-lived food-security crises that affect a greater fraction of the population compared with populations in agricultural livelihood zones. That pastoral regions require roughly twice as long to return to pre-drought levels of food security is particularly important because it demonstrates the magnitude of damage inflicted on pastoral livelihoods by drought.

Our findings demonstrate why actions taken to address pastoralist food security during times of drought need to acknowledge the difference between agricultural and pastoral livelihood systems, as well as socioeconomic differences in access to resources. To survive droughts, herders often sell livestock to purchase food from local markets, delaying a deterioration of food security initially ${ }^{34}$. As a drought intensifies, the price of grain rises, animal health deteriorates, the livestock:grain terms of trade collapse and it becomes difficult for pastoralists to meet dietary need $\mathrm{s}^{34-36}$. Post-drought herd reconstitution can take multiple years, and is considerably more expensive than the associated post-drought costs in agricultural zones $^{36-41}$. These short-term responses to drought are exacerbated by long-standing social and political differences between populations practising different livelihoods. The political exclusion of remote pastoral communities has led to a general lack of social services, physical infrastructure and delays in government provision of food aid during food crises $^{42-45}$.

One context in which our results may be useful is in improving food-security early warning systems. In particular, we provide evidence of how different hazards affect the food-security status of populations disaggregated by livelihood zones. Such information is applicable, for example, to improving the FEWS NET scenario development process ${ }^{36}$, which underpins food-security early warnings such as those recently issued for East Africa at the time of writing ${ }^{46}$. While our results cannot provide details on the effect of droughts or conflict on the income or assets of households, it can provide an indication of the food-security outcomes up to 24 months post-hazard in different livelihood zones. The persistence of 
Table 1 | Data sources for all variables used in the analysis

\begin{tabular}{lll} 
Variable & Dataset & Source \\
\hline Precipitation & $\begin{array}{l}\text { Climate Hazards group Infrared Precipitation with Stations } \\
\text { (CHIRPS) }\end{array}$ & https://www.chc.ucsb.edu/data/chirps \\
\hline Soil moisture & Global Land Evaporation Amsterdam Model (GLEAM) v.3.2a & https://www.gleam.eu/ \\
\hline $\begin{array}{l}\text { Vegetation stress } \\
\text { Enhanced Vegetation Index from the Moderate Resolution }\end{array}$ & https://modis.gsfc.nasa.gov/data/dataprod/mod13.php \\
\hline Locust presence & FAO Locust Hub & https://locust-hub-hafao.hub.arcgis.com/ \\
\hline Armed conflict & Armed Conflict Location and Event Data (ACLED) & https://acleddata.com/\#/dashboard \\
\hline Livelihood zones & Famine Early Warning System Network & https://fews.net/data \\
\hline IPC level & Famine Early Warning System Network & https://fews.net/data \\
\hline Food prices & FAO Food Prices Monitoring and Analysis & https://fpma.apps.fao.org/giews/food-prices/tool/public/\#/home \\
\hline Population & WorldPop gridded population data & https://www.worldpop.org/ \\
\hline
\end{tabular}

food insecurity in pastoral livelihoods for 2 years post-drought, for example, may be useful when determining whether droughts from 12-24 months ago should be considered in the problem specification step of the household economy analysis framework. Because FEWS NET food-security forecasts are less accurate in pastoral than in agricultural livelihood zones ${ }^{5}$, there is an opportunity to improve future forecasts of pastoral food insecurity. To move beyond more accurate food-security forecasts towards improving the services that can mitigate or prevent food crises in pastoral regions will require a combination of approaches, including improving precipitation predictions at time scales relevant for pastoral decision-making, providing economic and technical support during crises, improving pasture and water point management and monitoring, strengthening investment in water infrastructure in pastoral communities and along transhumance corridors, and promoting fodder cultivation and conservation along with grain storage not only among pastoralists and agropastoralists but also among agriculturalists on whom pastoralists rely to purchase fodder and grains.

\section{Methods}

Data. All data sources are described in Table 1. We use monthly soil moisture estimates from the Global Land Evaporation Amsterdam Model (GLEAM) v.3.2a (1981-2018), which uses satellite-observed surface $(0-10 \mathrm{~cm})$ soil moisture, vegetation optical depth, reanalysis air temperatures and a multisource precipitation product to derive surface soil moisture values at $0.25^{\circ}$ resolution

. Monthly precipitation data come from the Climate Hazards group Infrared Precipitation with Stations (CHIRPS; 1981-2018) aggregated to $0.25^{\circ}$ (ref. ${ }^{48}$ ). Vegetation data come from the MODIS satellite MOD13A1 V6 product generated every $16 \mathrm{~d}$ at $500 \mathrm{~m}$ spatial resolution since the year $2000^{49}$. We use the Enhanced Vegetation Index (EVI), which mitigates canopy background variations and maintains sensitivity in dense vegetation. The values are atmospherically corrected and masked for water, clouds, heavy aerosols and cloud shadows. The data are temporally averaged at the monthly level using Google Earth Engine, and then spatially averaged into a $0.5^{\circ}$ grid. Precipitation, soil moisture and EVI were all averaged over the previous 12 months before standardizing values as $z$ scores across years. The mean and standard deviation used in the $z$ score for a precipitation value in April, for example, was calculated using the May-April average for all years.

Estimates of food insecurity in this analysis are reported to be compatible with the IPC scale, which provides protocols to measure the severity of acute food insecurity using a five-point scale: minimal food insecurity, stressed, emergency, crisis and famine (phases $1-5$, respectively). The protocols and scale are designed to be applicable across countries. IPC levels are determined by consensus among analysts using all available information, including information on food consumption, changes to livelihood strategies, nutritional status, mortality, food availability, market prices and exposure to hazards ${ }^{15}$. IPC measurements, therefore, are not entirely independent from measures of drought or conflict, but they do represent a convergence of evidence beyond exposure to these hazards and represent a consensus-based synthesis of the best available information. IPC data have become prominent in the international community, used operationally by donors, international aid agencies and the United Nations as a means of determining food assistance needs and for formulating humanitarian response plans $s^{50,51}$. IPC data provide estimates of food security at the subnational level every three months from 2009 to 2016 and every four months from 2016 to present for countries in West Africa, East Africa and Southern Africa. Determining the true resolution of the IPC data, however, is difficult because analysts may use information from fine spatial scales to infer the food-security status of populations at larger spatial scales. IPC-compatible data are downloaded from the FEWS NET website and converted to a regular grid of $0.1^{\circ}, 0.25^{\circ}$ or $0.5^{\circ}$.

We adopt the livelihood zones from FEWS NET as one unit of analysis. FEWS NET produces maps of livelihood zones within each country, based on geographic and climatic zones, and where people generally have similar options for obtaining food, income and market access. These detailed maps are produced using a combination of expert and stakeholder input and Household Economic Analysis information. These livelihood zone maps are maintained by FEWS NET and are publicly available as shapefiles for geographic information systems applications (https://fews.net/sectors-topics/sectors/livelihoods). We use these shapefiles to derive simplified livelihood zones by aggregating the more detailed zones into the following classifications: coastal or riverine, pastoral, agropastoral, agricultural or urban. Note that we do not analyse urban livelihood zones here due to their limited extent. For all data processed using administrative units, we use the FEWS NET administrative level 1 and 2 shapefiles.

Data on the incidence of locusts are from the FAO Locust Hub (https:// locust-hub-hqfao.hub.arcgis.com/) for 2009-2018. Data are available only at annual resolution prior to 2012, so we use annual resolution data in this analysis. For IPC data reported in January and February, locust incidence from the previous year is used; for those data reported in April, June or July, the average of the current year and the previous year is used; and for IPC data reported in October, the current year is used. We count incidence of events in which locusts were detected, 'LOCPRESENT' $=1$ in the data, in each administrative unit level 1 per year.

For information on conflict in Africa we use the Armed Conflict Location and Event Data (ACLED) ${ }^{52}$. We use metrics of deaths or frequency of events occurring in the previous 12 months within a given administrative level 1 unit for all events in the battles, explosions/remote violence, riots or violence against civilians event categories. We choose administrative units because violent conflict in a location is likely to have knock-on effects that influence food access ${ }^{22}$ by affecting institutions or infrastructure. We tested the sensitivity of the analysis to the area of aggregation, using the intersection of administrative unit 2 and livelihood zones, and found the results to be similar. Similar to hydroclimate and vegetation variables, we sum deaths from conflict or frequency of conflict events over the preceding 12 months at each time step.

Food prices are from the FAO's GIEWS Food Prices Monitoring and Analysis (FPMA), which tracks monthly wholesale and retail prices at the crop and city-market level. We use standardized US-dollar-equivalent crop prices for maize, rice, wheat, cassava/gari, millet and sorghum. Missing monthly prices are linearly interpolated, and prices are normalized to the 2015 average. A country-level staple index is weighted by FAO country-level caloric dependence according to FAO Food Balance Sheets averaged over the 2000-2013 period for each crop and the crop's caloric content (NutVal 4.1). The 2000-2013 period was used to calculate average caloric dependency ratios due to data availability. Note that because price data are not available for all staple crops in every country, each country's index consists of the crops available in its city-markets.

We use the WorldPop database for annual, gridded population data (https:// www.worldpop.org/). WorldPop disaggregates census-level data to a regular grid using statistical models that incorporate survey, satellite and cellphone data $^{53}$. Using a modelling approach to disaggregate data avoids the problem of overestimating population in sparsely populated rural areas ${ }^{54}$. WorldPop data is aggregated up to a $0.1^{\circ}$ grid to match the IPC data.

We derive conservative estimates of the crude death rate related to food insecurity following Maxwell et al. ${ }^{8}$ by combining information from the IPC data with population data. Each IPC phase includes thresholds for indicators of food consumption, changes in livelihoods, acute malnutrition prevalence and crude death rate, measured as the number of people dying per day per 10,000 people. The most conservative estimate of mortality associated with each IPC phase $^{50}$ is multiplied by the population in that phase to derive a conservative estimate of 
crude death rate. This estimate of crude death rate is probably conservative and may not accurately represent actual mortality during events for this reason, but is useful as a means of comparing death rates across time and between events ${ }^{8}$. For example, IPC phase 3 is associated with a crude death rate range of $0.5-1$ person per 10,000 people per day, so the lower threshold of 0.5 is used. For IPC phases 4 and 5, the lower thresholds of 1 and 2 people per 10,000 people per day are used, respectively.

We define the analysis units used in the sensitivity and vulnerability analyses as the unique combination of livelihood zones and administrative level 2 units, which we create in ArcGIS by intersecting the two shapefiles and which will be referred to as analysis units hereafter. We use the FEWS NET administrative boundaries and livelihood zone boundaries to define these boundaries. We calculate the average precipitation, soil moisture or EVI anomaly at each time step within each analysis unit. We link the analysis unit to the appropriate administrative level 1 unit, as well as the associated conflict and locust exposures. FEWS NET IPC-compatible data on food security are reported at the livelihood zone or administrative unit, although there are considerable differences between the spatial resolution of reporting between countries. We chose the combination of administrative level 2 and livelihood zone as a compromise between the finest-scale data available in Ethiopia, for example, where data are reported at the Woreda level (administrative level 3), and more coarse reporting units such as Somalia, where food-security data are reported by livelihood zone.

Analysis. Food-security crises are dynamic phenomena with dimensions of magnitude, severity, spatial coverage and duration ${ }^{8}$. Even after the famine declaration many of the deaths occurred outside of the areas declared to be in famine. Consider, for example, the famine in Unity State, South Sudan; in 2017 famine conditions disappeared from the state but the number of people affected by food insecurity increased (for example, the severity of the crisis decreased while the magnitude increased) ${ }^{8}$. Consider also the 2010-2012 food-security crisis in Somalia, in which the majority of the excess mortality occurred either before famine conditions were declared or outside of the famine-affected regions, highlighting the importance of understanding spatial coverage and duration of a crisis in addition to severity ${ }^{8}$. Studying only the factors that affected the maximum severity of food insecurity in either of these examples provides at best an incomplete understanding of the crisis. In our analysis we characterize not only the severity of food-security crises by livelihood, but also the spatial coverage, magnitude and duration. Here we study a selection of the most food-insecure countries in Africa, meaning that by design the countries included in our analysis have a higher sensitivity to shocks than would many countries.

To analyse the prevalence of drought, conflict and locusts, in each livelihood zone we aggregate each variable over the analysis units, which are the unique combination of livelihood zones and administrative level 2 units. We calculate the soil moisture anomaly over the previous year, frequency of conflict over the previous year, frequency of adult locusts over the previous year and mode IPC value for each analysis unit at each time step. We next convert soil moisture values into measures of the coefficient of variation by dividing the standard deviation by the mean soil moisture value at the analysis unit level. We plot the distribution of each variable as a function of livelihood zone associated with the analysis unit in Fig. 2. Note that the soil moisture coefficients of variation are evaluated over the whole time period to provide one value per location and the distributions shown in Fig. 2 are over these values. In contrast, the IPC level is for a given month and year, as are the conflict frequency and frequency of locusts during the year prior. The distributions of IPC level, locusts and conflict in Fig. 2 are therefore across space and time.

To analyse the relation between the severity of food insecurity-as measured by the IPC phase-and drought, conflict or locusts, we plot distributions of each variable at the spatial scale of the analysis unit disaggregated by livelihood zone and IPC level (Fig. 3). The soil moisture distributions here are not the coefficients of variation as in Fig. 2, but instead the standardized $z$ scores of soil moisture over the year prior to the IPC observation. The frequency of locusts and conflict are likewise aggregated over the year prior to the IPC observation, although note that the time resolution of the locust data makes the time dimension inexact (Data).

To analyse the evolution of food-security status during droughts, we use an event composite analysis. We first identify all drought-related food-security crises by selecting each month in which the IPC scale indicated emergency, crisis or famine conditions present in a country that occurred concurrently with deficit precipitation over the previous year. Because we are interested in the multiyear evolution of these events, we identify the onset of the food insecurity and droughtagain, as measured using precipitation over the previous year-as the starting month and 24 months later as the end month. The start of events often coincided with the onset of the hunger season in which there were inadequate seasonal rains. We do not allow for overlapping events as this would double-count events in the composite. In the event of consecutive years of drought food-security crises, we choose the second year of the multiyear event. We use the national scale as the spatial scale for events because the food-security outcomes related to a drought depend on the economic and political response of social and political institutions.

There may be multiple food-insecurity events, therefore, relating to a single mesoscale drought. There are three events, for example, that relate to the 2011 failure of the long rains in the Horn of Africa because the drought affected Ethiopia, Somalia and Kenya ${ }^{27}$. Using this procedure, we identify 32 drought-related food-security events. By averaging all drought-related food-security crises from each country together, we isolate the influence of drought on food security while treating the effects of conflict as a random variable that averages out. This approach is supported by the lack of any discernible relationship between drought and conflict in the drought composite.

To attribute changes in food-security status to drought and conflict, we conducted a maximum covariance analysis (MCA). MCA is a methodology that identifies the patterns in two space-time datasets that explain the maximum covariance between them. Here we work with matrices that describe food security in space and time, $F$, and matrices that describe the hazards, $H$, that drive food insecurity. To construct $F$ and $H$ we first resample the soil moisture, precipitation, crude death rate and IPC data to a $0.5^{\circ}$ grid to match the EVI and conflict data resolution. We then construct the $N \times M$ food-security indicator matrix, $F$, where $N$ is the number of observations in space and $M$ the number of time steps, which are every 3-4 months (Data), by concatenating observations from gridded IPC data with observations from gridded estimates of the crude death rate. Next, we similarly constructed the $N \times M$ hazard matrix, $H$, where $N$ is the number of observations in space and $M$ the number of time steps, by concatenating precipitation anomalies, soil moisture anomalies, EVI anomalies, estimates of conflict frequency and estimates of deaths from conflict. Conflict and crude death rate data were log-transformed then de-meaned, food-security indicators were de-meaned and climate data were standardized before calculating the cross-covariance matrix used in the maximum covariance analysis. We conducted the analysis separately for each country by masking out all areas outside of the given country. We chose the country scale because while the incidence of violent conflict and drought crosses borders, the infrastructure, institutions and policies that determine food-security outcomes will depend on individual countries, which makes the country scale a natural domain for the analysis. After conducting the analysis for each country, we retained only the leading modes that were well separated from other modes based on their eigenvalues (not shown). We determine the spatial patterns of covariance between food security and hazard, namely:

$$
F H^{\mathrm{T}}=U \Sigma V^{\mathrm{T}}
$$

where $F H^{\mathrm{T}}$ is the cross-covariance matrix. The orthonormal matrices $U$ and $V$ then contain the spatial singular value decomposition modes corresponding to the data fields $F$ and $H$, respectively. $\Sigma$ is a matrix with the singular values on the diagonal. The leading modes represent the primary patterns of covariance between the two fields. We next recover the time-expansion coefficients for each mode, $k$, as:

$$
\begin{aligned}
& A_{k}=U_{k}^{\mathrm{T}} F \\
& B_{k}=V_{k}^{T} H
\end{aligned}
$$

such that we can reconstruct the portion of the total variance in the data related to each singular value decomposition mode as

$$
\begin{aligned}
& F_{k}=A_{k} U_{k} \\
& H_{k}=B_{k} V_{k}
\end{aligned}
$$

The maximum covariance analysis provides a series of spatial patterns ( $U$ and $V$ ) of the stresses to which food systems are subject (variations in precipitation, soil moisture, vegetative stress, conflict frequency and conflict intensity-contained within $V$ ) and the associated spatial pattern of the response of food-security indicators (variations in the IPC level or associated crude death rate-contained within $U$ ). A spatial pattern of widespread drought and vegetative stress, for example, coincides with degraded food security in the same region in the second MCA mode calculated for Ethiopia (Supplementary Fig. 4).

The eigenvalues of the MCA indicate the covariance between the hazard variables matrix, $H$, and the food-security variables matrix, $F$, explained by each mode. The extent to which each mode explains the variance of the individual variables within each matrix can be calculated by comparing the variance of the reconstruction using each mode to the total variance of the field (for example, by comparing the field reconstructed from mode $k, F_{k}$, to the total variance of the original field $F$ ).

The separable, leading modes are categorized as drought-related or conflict-related modes based on pattern loadings, time-expansion coefficients and variance explained in the conflict covariates (conflict-related deaths and frequency of conflict) or the physical climate variables (precipitation, soil moisture and EVI). Before attributing any mode to being related to either physical variables or conflict, we reference external literature to cross-check the associations in the maximum covariance analysis. Our attribution for each mode used in Fig. 6 is shown below.

In Ethiopia the first two modes were well separated from the remaining modes, with both modes loading heavily on physical variables and less strongly on conflict-related variables (Supplementary Figs. 4 and 5). The first mode describes increased precipitation, wet soils, little vegetative stress and relatively food-secure conditions in the Somali region of Ethiopia. The second mode 
describes widespread drought and vegetative stress in the northwest of Ethiopia, which coincides with food-insecure conditions in the same regions. Both of these first two modes were labelled to be primarily physical climate-related modes. That recent food-security crises in Ethiopia are predominantly attributable to drought is supported by the interview-based analysis of Maxwell and Hailey ${ }^{4}$, which found the 2011 food-security crisis to be drought driven and the 2015-2018 crisis to be largely attributable to drought, although they note that localized conflict may be a contributing factor in the latter case. Drought, in fact, affected food security in some portion of Ethiopia nearly every year between 2009 and 2018, including major events in 2009, 2011, 2015 and 2017 9,27,28.

In Somalia we retain only the first mode, which loads on both conflict-related variables and on physical climate-related variables (Fig. 6). This mode loads primarily on the confirmed 2011 famine and the averted 2017 famine, which Maxwell and Hailey attribute to both drought and conflict ${ }^{4}$. Maxwell and Majid outline the ways that violent conflict delayed the government and humanitarian response to the drought in 2011, which allowed food security to deteriorate considerably before intervention ${ }^{26}$. This mode is further discussed in the main text.

In Kenya the first mode is retained and corresponds to wet growing conditions, with little vegetative stress that corresponds to food-secure conditions throughout the country (Supplementary Fig. 6). This mode was labelled as a physical climate mode. Maxwell and Hailey confirm that recent food insecurity in Kenya was mostly affected by drought ${ }^{4}$

In Nigeria we retain only the first mode, which describes a deterioration of food security in the northeast coincident with significant increases in the frequency of conflict (Fig. 5 and Supplementary Fig 7). While this mode loads also on insignificant trends towards dry conditions in Nigeria, the relatively drier conditions do not correspond in space to significant changes in food-security status, while the spatial loadings on conflict-related variables and changes in food-security status occurred simultaneously in the northeast. This mode describes the rise of Boko-Haram-related violence centred in the northeast state of Borno in Nigeria that has disrupted livelihoods, displaced people and reduced households' ability to access food, which led to persistent food insecurity including a possible, but unconfirmed, famine ${ }^{11-13}$. We furthermore see a sharp increase in food price inflation in Nigeria in 2016 (results not shown) related to conflict and oil pipeline sabotage in the Niger Delta, which reduced national oil production by over $50 \%^{29}$. Reduced government revenue, already low due to the drop in global oil price, contributed to a recession in 2016 and a major currency devaluation, which produced high domestic inflation

In Sudan and South Sudan we retain two modes of variability, which are both separable from the remaining modes. The first mode describes wet conditions coincident with little vegetative stress, but an increased frequency of conflict across the domain that coincides with higher rates of food insecurity. This mode describes the statistically significant increase in conflict and decrease in food security over the domain (Fig. 5 and Supplementary Figs. 8 and 9). We therefore attribute this mode to be primarily conflict-related. The second mode describes widespread precipitation deficits, dry soils and vegetation stress, with soil moisture drought particularly severe in South Sudan. This mode loads heavily on the droughts of 2010 and 2017, which, in combination with conflict during 2017-2019, led to food insecurity in the region ${ }^{8,21,30}$. The conflict in South Sudan affected food security directly, but also reduced economic activity by disrupting oil production ${ }^{31}$.

We used the attributed, reconstructed, IPC variable from the MCA modes for Sudan, South Sudan, Nigeria, Kenya, Somalia and Ethiopia to estimate the relative importance of each trigger in each livelihood zone. We sum the population in areas with reconstructed IPC levels that reach crisis levels (IPC level $\geq 3$ ). In South Sudan, where two modes are used for different triggers, we first attribute based on the reconstruction using the conflict mode (mode 1, Supplementary Fig. 8) followed by the inclusion of the conflict and drought mixed mode (mode 2, Supplementary Fig. 9). Food insecurity in all other countries and for all other triggers not included in the attribution analysis (for example, flooding, micro- and macro-economic shocks) were categorized as 'other'. The bar charts in Fig. 7 for each livelihood are calculated by summing the populations living in areas classified in crisis levels of food insecurity attributed to each trigger over the stated time period and converting to a percentage based on the total population living in areas classified in crisis levels of food insecurity.

Statistics. We analyse statistical significance of differences in prevalence of hazards using pairwise comparisons between the pastoral distributions and each other livelihood zone using a two-tailed Student's $t$ test. For exposure to drought compared to other livelihoods, $P=0.0$ for all pairwise comparisons, with the number of observations as follows: pastoralist, $n=10,202$; agropastoral, $n=40,768$; agricultural, $n=50,361$; coastal or riverine, $n=6,965$. For exposure to conflict compared with other livelihoods, $P<1 \times 10^{-7}$ for all pairwise comparisons, with the number of observations as follows: pastoralist, $n=7,168$; agropastoral, $n=22,7663$; agricultural, $n=34,933$; coastal or riverine, $n=5,325$. For exposure to locusts compared with other livelihoods, $P=0.0$ for all pairwise comparisons, with the number of observations as follows: pastoralist, $n=10,021$; agropastoral, $n=40,041$; agricultural, $n=50,425$; coastal or riverine, $n=7,091$.

Reporting summary. Further information on research design is available in the Nature Research Reporting Summary linked to this article.

\section{Data availability}

All data used as part of this research are publicly available from the sources listed in Table 1.

\section{Code availability}

All code available upon request.

Received: 6 November 2020; Accepted: 16 June 2021; Published online: 12 August 2021

\section{References}

1. The State of Food Security and Nutrition in the World 2019: Safeguarding Against Economic Slowdowns and Downturns (FAO, IFAD, UNICEF, WFP, WHO, 2019).

2. Salih, A. A., Baraibar, M., Mwangi, K. K. \& Artan, G. Climate change and locust outbreak in East Africa. Nat. Clim. Change 10, 584-585 (2020).

3. Impact of Desert Locust Infestation on Household Livelihoods and Food Security in Ethiopia (Food and Agriculture Organization, 2020).

4. Maxwell, D. \& Hailey, P. The Politics of Information and Analysis in Famines and Extreme Emergencies: Synthesis of Findings from Six Case Studies (Feinstein International Center, 2020).

5. Krishnamurthy, P. K., Choularton, R. J. \& Kareiva, P. Dealing with uncertainty in famine predictions: how complex events affect food security early warning skill in the greater Horn of Africa. Glob. Food Sec. 26, 100374 (2020).

6. Majid, N. \& McDowell, S. Hidden dimensions of the Somalia famine. Glob. Food Sec. 1, 36-42 (2012).

7. Maxwell, D., Majid, N., Adan, G., Abdirahman, K. \& Kim, J. J. Facing famine: Somali experiences in the famine of 2011. Food Policy 65, 63-73 (2016).

8. Maxwell, D., Khalif, A., Hailey, P. \& Checchi, F. Determining famine: multi-dimensional analysis for the twenty-first century. Food Policy 92, $1-13$ (2020).

9. Mohamed, A. A. Food security situation in Ethiopia: a review study. Int. J. Health Econ. Policy 2, 86-96 (2017).

10. Devereux, S. Food Insecurity in Ethiopia (Institute for Development Studies, 2000).

11. Ayinde, I. A., Otekunrin, O. A., Akinbode, S. O. \& Otekunrin, O. A. Food security in Nigeria: impetus for growth and development. J. Agric. Econ. 6, 800-813 (2020).

12. Otekunrin, O. A., Otekunrin, O. A., Momoh, S. \& Ayinde, I. A. How far has Africa gone in achieving the zero hunger target? Evidence from Nigeria. Glob. Food Sec. 22, 1-12 (2019).

13. Azad, M., Crawford, E. E. \& Kaila, H. K. Conflict and Violence in Nigeria: Results from the North East, North Central, and South South Zones (World Bank, 2018).

14. Young, H., Jaspers, S., Brown, R., Frize, J. \& Khogali, H. Food-Security Assessments in Emergencies: A Livelihoods Approach (Overseas Development Institute, 2001).

15. Technical Manual Version 3.0: Evidence and Standards for Better Food Security and Nutrition Decisions (Integrated Food Security Phase Classification Global Partners, 2019).

16. de Perez, E. C. et al. From rain to famine: assessing the utility of rainfall observations and seasonal forecasts to anticipate food insecurity in East Africa. Food Sec. 11, 57-68 (2019).

17. Verpoorten, M. Household coping in war- and peacetime: cattle sales in Rwanda, 1991-2001. J. Dev. Econ. 88, 67-86 (2009).

18. Helman, D., Zaitchik, B. F. \& Funk, C. Climate has contrasting direct and indirect effects on armed conflicts. Environ. Res. Lett. 15, 104017 (2020).

19. Buhaug, H., Benjaminsen, T. A., Sjaastad, E. \& Theisen, O. M. Climate variability, food production shocks, and violent conflict in sub-Saharan Africa. Environ. Res. Lett. 10, 125015 (2015).

20. Von Uexkull, N. Sustained drought, vulnerability and civil conflict in sub-Saharan Africa. Polit. Geogr. 43, 16-26 (2014).

21. Brück, T. \& d'Errico, M. Food security and violent conflict: introduction to the special issue. World Dev.117, 167-171 (2019).

22. Martin-Shields, C. P. \& Stojetz, W. Food security and conflict: empirical challenges and future opportunities for research and policy making on food security and conflict. World Dev. 119, 150-164 (2019).

23. Justino, P. Nutrition, Governance and Violence: A Framework for the Analysis of Resilience and Vulnerability to Food Insecurity in Contexts of Violent Conflict HiCN Working Paper 132 (Institute of Development Studies at the University of Sussex, 2012).

24. Arias, M. A., Ibáñez, A. M. \& Zambrano, A. Agricultural production amid conflict: separating the effects of conflict into shocks and uncertainty. World Dev. 119, 165-184 (2019).

25. Federal Republic of Somalia Systematic Country Diagnostic (World Bank, 2018). 
26. Maxwell, D. G. \& Majid, N. Famine in Somalia: Competing Imperatives, Collective Failures, 2011-12 (Oxford Univ. Press, 2016).

27. Anderson, W. et al. Towards an integrated soil moisture drought monitor for East Africa. Hydrol. Earth Sys. Sci. 16, 2893-2913 (2012).

28. Funk, C. et al. Examining the role of unusually warm Indo-Pacific sea-surface temperatures in recent African droughts. Q. J. R. Meteorol. Soc. 144 360-383 (2018).

29. Sabotage on Nigeria's Oil-Exporting NCTL Pipeline Caused Significant Production Losses (Reuters, 2019).

30. Trends in Acute Food Insecurity, 2013-2018: Five-year Conflict in South Sudan Drives Significant Increase in Assistance Needs and Famine Risk (Famine Early Warning System Network, 2018); https://fews.net/east-africa/south-sudan/ special-report/december-2018

31. Dihel, N. C. \& Pape, U. J. South Sudan-Economic Update: Taming the Tides of High Inflation-Policy Options (World Bank, 2017).

32. Anna, C. \& Lederer, E. US urges Ethiopia's PM to allow 'immediate' help to Tigray. The Washington Post (4 February 2021); https://apnews.com/article/ kenya-ethiopia-united-nations-eritrea-e183d672de7da4c9bf6fae7d24f3a3e0

33. Osman, A., Olesambu, E. \& Balfroid, C. Pastoralism in Africa's Drylands: Reducing Risks, Addressing Vulnerability and Enhancing Resilience (Food and Agriculture Organization, 2018).

34. Hein, L., Metzger, M. J. \& Leemans, R. The local impacts of climate change in the Ferlo, Western Sahel. Clim. Change 93, 465-483 (2009).

35. Devereux, S. Why does famine persist in Africa? Food Sec. 1, 25-35 (2009).

36. Integrating Livestock Herd Dynamics into Scenario Development Guidance Document 6 (Famine Early Warning System Network, 2018).

37. Hesse, C. \& Cotula, L. Climate Change and Pastoralists: Investing in People to Respond to Adversity (IIED, 2006).

38. Toulmin, C. Livestock Losses and Post-drought Rehabilitation in Sub-Saharan Africa (ILCA, 1985).

39. Lesnoff, M., Corniaux, C. \& Hiernaux, P. Sensitivity analysis of the recovery dynamics of a cattle population following drought in the Sahel region. Ecol. Modell. 232, 28-39 (2012).

40. White, C. Herd reconstitution: the role of credit among Wodaabe herders in Central Niger. Camb. Anthropol. 9, 30-42 (1984).

41. Ahmed, A. G. M., Azeze, A., Babiker, M. \& Tsegaye, D. Post Drought Recovery Strategies Among the Pastoral Households in the Horn of Africa: A Review (OSSREA, 2002)

42. Coast, E. Maasai socioeconomic conditions: a cross-border comparison. Hum. Ecol. 30, 79-105 (2002).

43. Raleigh, C. Political marginalization, climate change, and conflict in African Sahel states. Int. Stud. Rev. 12, 69-86 (2010).

44. Smith, K., Barrett, C. B. \& Box, P. W. Participatory risk mapping for targeting research and assistance: with an example from East African pastoralists. World Dev. 28, 1945-1959 (2000).

45. Keen, D. et al. The Benefits of Famine: A Political Economy of Famine and Relief in Southwestern Sudan 1983-89 (James Currey, 2008).

46. Funk, C. Ethiopia, Somalia and Kenya face devastating drought. Nature 586, 645 (2020)
47. Martens, B. et al. Gleam v3: satellite-based land evaporation and root-zone soil moisture. Geosci. Model Dev. 10, 1903-1925 (2017).

48. Funk, C. et al. The climate hazards infrared precipitation with stations-a new environmental record for monitoring extremes. Sci. Data 2 , 150066 (2015)

49. Didan, K. Mod13q1 MODIS/TERRA Vegetation Indices 16-day l3 Global 250m Sin Grid v006. NASA EOSDIS Land Processes DAAC 10 (NASA, 2015).

50. Young, H. \& Jaspars, S. Review of Nutrition and Mortality Indicators for the Integrated Food Security Phase Classification (IPC): Reference Levels and Decision-Making (Inter-Agency Standing Committee Nutrition Cluster and ECHO, 2009).

51. Integrated Food Security Phase Classification: Technical Manual Version 2.0: Evidence and Standards for Better Food Security Decisions (Food and Agriculture Organization, 2012).

52. Raleigh, C., Linke, A., Hegre, H. \& Karlsen, J. Introducing ACLED: an armed conflict location and event dataset: special data feature. J. Peace Res. 47, 651-660 (2010)

53. Tatem, A. J. WorldPop, open data for spatial demography. Sci. Data 4, 170004 (2017)

54. Leyk, S. et al. The spatial allocation of population: a review of large-scale gridded population data products and their fitness for use. Earth Syst. Sci. Data 11, 1385-1409 (2019).

\section{Acknowledgements}

This project was supported by ACToday, a Columbia World Project. W.A. acknowledges funding from the Earth Institute Postdoctoral Fellow Program. R.S., S.M., E.I.-N., W.S., A.d.S. and F.C. were supported by NSF award OIA 1934798

\section{Author contributions}

W.A. designed the experiments. W.A., C.T., S.M., E.I.-N., R.S., W.S., F.C. and A.d.S. analysed the data and wrote the paper. W.A., C.T., S.M., W.S., D.M. and K.M. contributed analysis tools and materials to the research.

\section{Competing interests}

The authors declare no competing interests.

\section{Additional information}

Supplementary information The online version contains supplementary material available at https://doi.org/10.1038/s43016-021-00327-4.

Correspondence and requests for materials should be addressed to W.A.

Peer review information Nature Food thanks Chris Funk and the other, anonymous, reviewer(s) for their contribution to the peer review of this work.

Reprints and permissions information is available at www.nature.com/reprints. Publisher's note Springer Nature remains neutral with regard to jurisdictional claims in published maps and institutional affiliations.

(C) The Author(s), under exclusive licence to Springer Nature Limited 2021 


\section{natureportfolio}

Corresponding author(s): Weston Anderson

Last updated by author(s): Jun 11,2021

\section{Reporting Summary}

Nature Portfolio wishes to improve the reproducibility of the work that we publish. This form provides structure for consistency and transparency in reporting. For further information on Nature Portfolio policies, see our Editorial Policies and the Editorial Policy Checklist.

\section{Statistics}

For all statistical analyses, confirm that the following items are present in the figure legend, table legend, main text, or Methods section. $\mathrm{n} / \mathrm{a} \mid$ Confirmed

$\bigotimes$ The exact sample size $(n)$ for each experimental group/condition, given as a discrete number and unit of measurement

$\square$ A statement on whether measurements were taken from distinct samples or whether the same sample was measured repeatedly

The statistical test(s) used AND whether they are one- or two-sided

Only common tests should be described solely by name; describe more complex techniques in the Methods section.

$\bigotimes$ A description of all covariates tested

$\square$ A description of any assumptions or corrections, such as tests of normality and adjustment for multiple comparisons

$\square$ A full description of the statistical parameters including central tendency (e.g. means) or other basic estimates (e.g. regression coefficient) $\triangle$ AND variation (e.g. standard deviation) or associated estimates of uncertainty (e.g. confidence intervals)

$叉$ For null hypothesis testing, the test statistic (e.g. $F, t, r)$ with confidence intervals, effect sizes, degrees of freedom and $P$ value noted $\triangle$ Give $P$ values as exact values whenever suitable.

Х $\square$ For Bayesian analysis, information on the choice of priors and Markov chain Monte Carlo settings

Х $\square$ For hierarchical and complex designs, identification of the appropriate level for tests and full reporting of outcomes

$\bigotimes \square$ Estimates of effect sizes (e.g. Cohen's $d$, Pearson's $r$ ), indicating how they were calculated

Software and code

Pohcy information about availability of computer code

Data collection No new data was collected for this study

Data analysis All data analyzed in Python v3.5.4

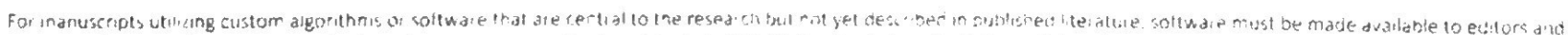

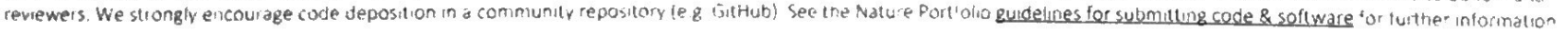

Data

Policy information about avallability of data

All manuscripts must include a data availability statement. This statement should provide the following information, where applicable:

- Accession codes, unique identifiers, or web links for publicly available datasets

- A description of any restrictions on data availability

- For clinical datasets or third party data, please ensure that the statement adheres to our policy

All data used as part of this research is publicly available from the sources listed in Table 1. 
Please select the one below that is the best fit for your research. If you are not sure, read the appropriate sections before making your selection.

$\square$ Life sciences

Behavioural \& social sciences $\square$ Ecological, evolutionary \& environmental sciences

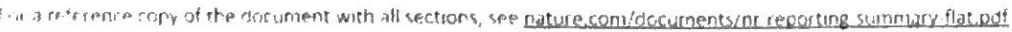

\section{Ecological, evolutionary \& environmental sciences study design}

All studies must disclose on these points even when the disclosure is negative

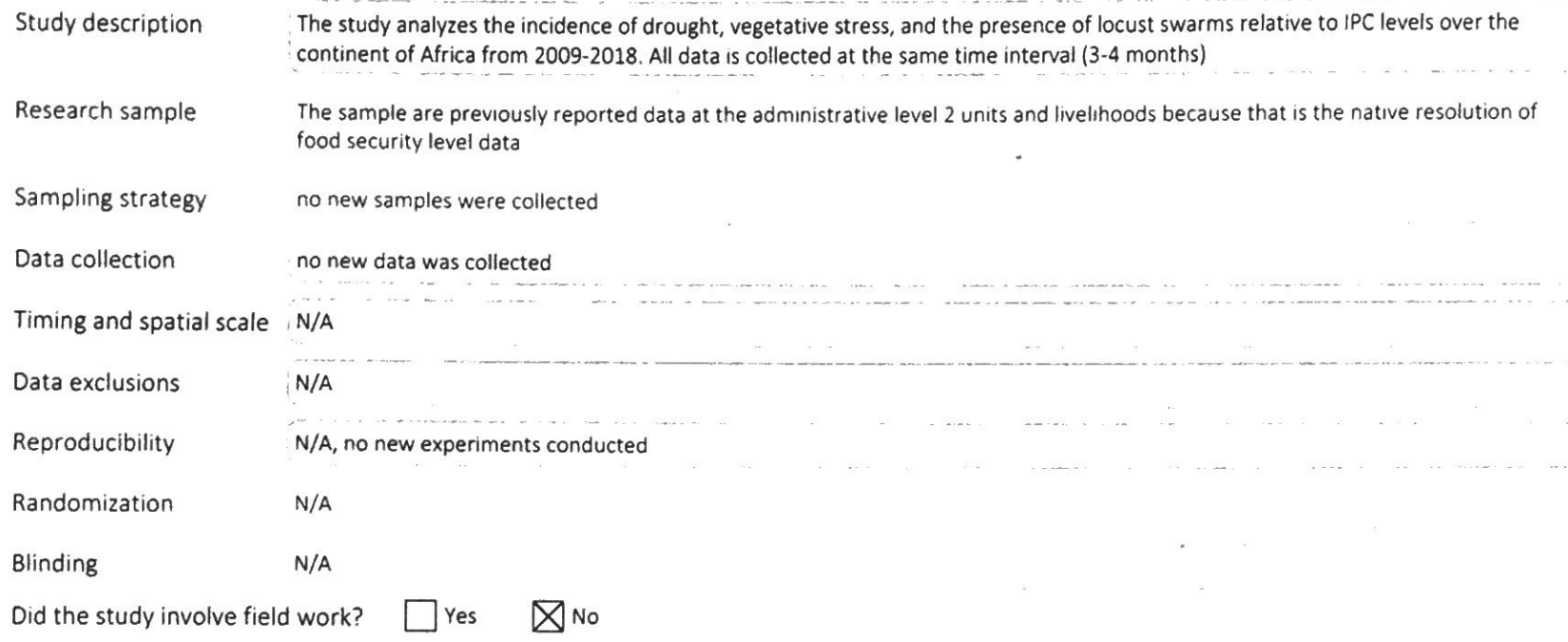

\section{Reporting for specific materials, systems and methods}

We require information from authors about some tvpes of materids, experimental systems and metlods used in many studies Here indicate whether each material.

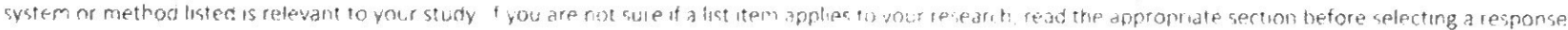

Materials \& experimental systems \begin{tabular}{l|l}
$\mathrm{n} / \mathrm{a}$ & Involved in the study
\end{tabular} Methods

\begin{tabular}{l|l}
$\bigotimes$ & $\square$ Antibodies \\
$\square$ & $\square$ Eukaryotic cell lines \\
$\square$ & $\square$ Palaeontology and archaeology \\
$\square$ & $\square$ Anımals and other organisms \\
$\square$ & $\square$ Human research participants \\
$\square$ & $\square$ Clinical data \\
$\bigotimes \mid \square$ Dual use research of concern
\end{tabular}

$\mathrm{n} / \mathrm{a}$ Involved in the study

\ $\square$ Chip-seq

\ $\square$ Flow cytometry

$\triangle \square$ MRI-based neuroimaging 


\section{Terms and Conditions}

Springer Nature journal content, brought to you courtesy of Springer Nature Customer Service Center GmbH ("Springer Nature").

Springer Nature supports a reasonable amount of sharing of research papers by authors, subscribers and authorised users ("Users"), for smallscale personal, non-commercial use provided that all copyright, trade and service marks and other proprietary notices are maintained. By accessing, sharing, receiving or otherwise using the Springer Nature journal content you agree to these terms of use ("Terms"). For these purposes, Springer Nature considers academic use (by researchers and students) to be non-commercial.

These Terms are supplementary and will apply in addition to any applicable website terms and conditions, a relevant site licence or a personal subscription. These Terms will prevail over any conflict or ambiguity with regards to the relevant terms, a site licence or a personal subscription (to the extent of the conflict or ambiguity only). For Creative Commons-licensed articles, the terms of the Creative Commons license used will apply.

We collect and use personal data to provide access to the Springer Nature journal content. We may also use these personal data internally within ResearchGate and Springer Nature and as agreed share it, in an anonymised way, for purposes of tracking, analysis and reporting. We will not otherwise disclose your personal data outside the ResearchGate or the Springer Nature group of companies unless we have your permission as detailed in the Privacy Policy.

While Users may use the Springer Nature journal content for small scale, personal non-commercial use, it is important to note that Users may not:

1. use such content for the purpose of providing other users with access on a regular or large scale basis or as a means to circumvent access control;

2. use such content where to do so would be considered a criminal or statutory offence in any jurisdiction, or gives rise to civil liability, or is otherwise unlawful;

3. falsely or misleadingly imply or suggest endorsement, approval, sponsorship, or association unless explicitly agreed to by Springer Nature in writing;

4. use bots or other automated methods to access the content or redirect messages

5. override any security feature or exclusionary protocol; or

6. share the content in order to create substitute for Springer Nature products or services or a systematic database of Springer Nature journal content.

In line with the restriction against commercial use, Springer Nature does not permit the creation of a product or service that creates revenue, royalties, rent or income from our content or its inclusion as part of a paid for service or for other commercial gain. Springer Nature journal content cannot be used for inter-library loans and librarians may not upload Springer Nature journal content on a large scale into their, or any other, institutional repository.

These terms of use are reviewed regularly and may be amended at any time. Springer Nature is not obligated to publish any information or content on this website and may remove it or features or functionality at our sole discretion, at any time with or without notice. Springer Nature may revoke this licence to you at any time and remove access to any copies of the Springer Nature journal content which have been saved.

To the fullest extent permitted by law, Springer Nature makes no warranties, representations or guarantees to Users, either express or implied with respect to the Springer nature journal content and all parties disclaim and waive any implied warranties or warranties imposed by law, including merchantability or fitness for any particular purpose.

Please note that these rights do not automatically extend to content, data or other material published by Springer Nature that may be licensed from third parties.

If you would like to use or distribute our Springer Nature journal content to a wider audience or on a regular basis or in any other manner not expressly permitted by these Terms, please contact Springer Nature at

onlineservice@springernature.com 